\title{
Understanding Overpressure in the FAA Aerosol Can Test by $\mathrm{C}_{3} \mathrm{H}_{2} \mathrm{~F}_{3} \mathrm{Br}$ (2-
} $\mathrm{BTP})^{*}$

\author{
G.T. Linteris ${ }^{1}$, V.I. Babushok ${ }^{1}$, J.L. Pagliaro ${ }^{1}$,D.R. Burgess ${ }^{2}$, J.A. Manion ${ }^{2}$, F. Takahashi ${ }^{3}$, V. \\ Katta ${ }^{4}$ and P.T. Baker ${ }^{5}$ \\ ${ }^{1}$ Fire Research Division; ${ }^{2}$ Chemical Sciences Division; \\ National Institute of Standards and Technology; Gaithersburg, MD, 20899, USA \\ ${ }^{3}$ Case Western Reserve University; Cleveland, OH 44106, USA \\ ${ }^{4}$ Innovative Scientific Solutions, Inc.; Dayton, OH 45440, USA \\ ${ }^{5}$ The Boeing Company; Seattle WA, 98124, USA
}

Accepted for publication in: Combustion and Flame

Date: Oct. 14, 2015

Corresponding author:

Gregory T. Linteris

National Institute of Standards and Technology

Engineering Laboratory

100 Bureau Dr.; Stop 8665

Gaithersburg MD 20899-8665, USA

linteris@nist.gov

ph: 301-975-2283; fax: 301-975-4052

* Official contribution of NIST, not subject to copyright in the United States. Certain commercial equipment, instruments, and materials are identified in this paper to adequately specify the procedure. Such identification does not imply recommendation or endorsement by the National Institute of Standards and Technology. 


\section{Abstract}

Thermodynamic equilibrium calculations, as well as perfectly-stirred reactor (PSR) simulations with detailed reaction kinetics, are performed for a potential halon replacement, $\mathrm{C}_{3} \mathrm{H}_{2} \mathrm{~F}_{3} \mathrm{Br}$ (2-BTP, $\mathrm{C}_{3} \mathrm{H}_{2} \mathrm{~F}_{3} \mathrm{Br}$, 2-Bromo-3,3,3-trifluoropropene), to understand the reasons for the unexpected enhanced combustion rather than suppression in a mandated FAA test. The high pressure rise with added agent is shown to depend on the amount of agent, and is wellpredicted by an equilibrium model corresponding to stoichiometric reaction of fuel, oxygen, and agent. A kinetic model for the reaction of $\mathrm{C}_{3} \mathrm{H}_{2} \mathrm{~F}_{3} \mathrm{Br}$ in hydrocarbon-air flames has been applied to understand differences in the chemical suppression behavior of $\mathrm{C}_{3} \mathrm{H}_{2} \mathrm{~F}_{3} \mathrm{Br}$ vs. $\mathrm{CF}_{3} \mathrm{Br}$ in the FAA test. Stirred-reactor simulations predict that in the conditions of the FAA test, the inhibition effectiveness of $\mathrm{C}_{3} \mathrm{H}_{2} \mathrm{~F}_{3} \mathrm{Br}$ at high agent loadings is relatively insensitive to the overall stoichiometry (for fuel-lean conditions), and the marginal inhibitory effect of the agent is greatly reduced, so that the mixture remains flammable over a wide range of conditions. Most important, the flammability of the agent-air mixtures themselves (when compressively preheated), can support low-strain flames which are much more difficult to extinguish than the easy-to extinguish, high-strain primary fireball from the impulsively released fuel mixture. Hence, the exothermic reaction of halogenated hydrocarbons in air should be considered in other situations with strong ignition sources and low strain flows, especially at preheated conditions. 
Keywords: $\mathrm{C}_{3} \mathrm{H}_{2} \mathrm{~F}_{3} \mathrm{Br} ; \mathrm{C}_{3} \mathrm{H}_{2} \mathrm{~F}_{3} \mathrm{Br} ;$ 2-BTP; Cargo Bay Fire Suppression; Halon Replacements; $\mathrm{CF}_{3} \mathrm{Br}$, Clean Agent Fire Suppression

\section{Introduction and Background}

Production of the fire suppressant $\mathrm{CF}_{3} \mathrm{Br}$ (Halon 1301) has been banned by the Montreal Protocol, because of its high ODP (ozone depletion potential). A critical-use exemption has been granted to the aviation industry for use of recycled halon in cargo bay fire suppression; however, the European Union requires replacement of halon in new-design aircraft by 2018, and in existing aircraft by 2040. Low-ODP replacement agents have been proposed, but they all failed the most challenging test: the US Federal Aviation Administration (FAA) Aerosol Can Test (FAA-ACT) [1], which is part of the FAA's Minimum Performance Standard [2]. Moreover, all the replacement agents tested to date, $\mathrm{C}_{2} \mathrm{HF}_{5}$ (HFC-125), $\mathrm{C}_{3} \mathrm{H}_{2} \mathrm{~F}_{3} \mathrm{Br}\left(\mathrm{C}_{3} \mathrm{H}_{2} \mathrm{~F}_{3} \mathrm{Br}\right.$, 2-Bromo-3,3,3trifluoropropene), and $\mathrm{C}_{6} \mathrm{~F}_{12} \mathrm{O}$ (Novec 1230) [3], when added at concentrations less than that required to completely suppress an explosion in a simulated cargo bay, produce higher peak pressures than with no added agent at all. In contrast, addition of $\mathrm{CF}_{3} \mathrm{Br}$ at any concentration does not increase the pressure rise. Typically, the fluorinated agents act as fire suppressants, and based on the previous work $[4,5]$, they would be expected to extinguish-or at least weaken - the FAA aerosol can test explosions. Previous work [6-8] has explained the behavior of the agents $\mathrm{C}_{2} \mathrm{HF}_{5}, \mathrm{C}_{6} \mathrm{~F}_{12} \mathrm{O}$, and $\mathrm{CF}_{3} \mathrm{Br}$ (for which kinetic mechanisms were available or developed). The unexpected result is particularly surprising for 2-BTP since it contains the element $\mathrm{Br}$, which is known to be a much more effective flame inhibitor than $\mathrm{F}$. Using a recently developed kinetic mechanism for $\mathrm{C}_{3} \mathrm{H}_{2} \mathrm{~F}_{3} \mathrm{Br}$ [9], the present work analyzes the behavior 
of $\mathrm{C}_{3} \mathrm{H}_{2} \mathrm{~F}_{3} \mathrm{Br}$ (2-BTP) in the FAA-ACT, and compares it to $\mathrm{CF}_{3} \mathrm{Br}$, to understand the reasons for the different effectiveness.

Enhanced combustion by fire suppressants has been noted in previous studies, as briefly reviewed in ref. [7]. Both promotion and inhibition have been observed in ignition [10] and detonation [11] experiments and in ignition delay calculations [12]. Wider lean flammability limits have been measured [13-16] in the presence of halogenated hydrocarbons; and in constant volume combustion systems, the pressure rise, as well as its rate of rise, have shown promotion for some conditions [16]. Experiments with high-speed turbulent flames in a detonation/deflagration tube [17] have shown more vigorous combustion, or inhibition, of propane- and ethylene-air mixtures with addition of $\mathrm{CF}_{3} \mathrm{l}, \mathrm{CF}_{3} \mathrm{Br}$, or various hydrofluorocarbons, depending upon the agent, its loading, and the fuel. Co-flow diffusion flame experiments and simulations have indicated an increased total heat release with halogenated hydrocarbons added to either the fuel [18] or air stream $[19,20]$. While specific examples of enhanced flammability in the presence of HFC fire suppressants have been described, little has been done until recently to understand the combustion enhancement.

Tests with $\mathrm{C}_{3} \mathrm{H}_{2} \mathrm{~F}_{3} \mathrm{Br}$ have shown it to be a promising halon replacement, with required suppression concentrations much like those of $\mathrm{CF}_{3} \mathrm{Br}$. Similar to $\mathrm{CF}_{3} \mathrm{Br}$, it contains both $\mathrm{Br}$ and $\mathrm{CF}_{3}$ (note that bromine is the halogen with the strongest flame inhibiting action [21], so $\mathrm{C}_{3} \mathrm{H}_{2} \mathrm{~F}_{3} \mathrm{Br}$ should be more effective than the HFCs). Using co-flow diffusion flames with heptane (in the NMERI 5/8-scale cup-burner), Moore et al. [22] measured the minimum extinguishing concentration (MEC) for 2-BTP in air to be $2.6 \%$ (volume fraction in the oxidizer), as compared to $2.9 \%$ for halon 1301 . Table 2 shows the minimum extinguishment concentration for 
heptane-air cup-burner flames with added agent in the air stream. Using the Kidde cup-burner (full-size, and other small physical differences) with heated heptane $\left(55^{\circ} \mathrm{C}\right)$, Grigg et al. [23] obtained MEC values of $4.6 \%$ and $3.6 \%$, respectively; and in the suppression of small-scale class A or class $\mathrm{B}$ fires, they found 2-BTP and halon $1211\left(\mathrm{CF}_{2} \mathrm{ClBr}\right)$ required similar suppressant mass [23]. Researchers have studied the performance of 2-BTP blended with nitrogen [24] (heptane cup-burner flames) or with water mist [25] (gasoline pan fires): 2-BTP performed well, requiring volume fractions and masses similar to halon 1301 or halon 1211, respectively. Notwithstanding, when 2-BTP was added at sub-inerting concentrations to the FAA-ACT (a constant-volume experiment), it created the largest overpressure of any agent tested. Hence, further research is warranted to understand the unexpected behavior.

Previous work $[6,7]$ used thermodynamic analyses to predict the experimental pressure rise for addition of $\mathrm{C}_{2} \mathrm{HF}_{5}, \mathrm{C}_{3} \mathrm{H}_{2} \mathrm{~F}_{3} \mathrm{Br}$, and $\mathrm{C}_{6} \mathrm{~F}_{12} \mathrm{O}$ at sub-extinguishing volume fractions in the FAA-ACT. In subsequent work $[7,8]$, the kinetic behavior of $\mathrm{CF}_{3} \mathrm{Br}, \mathrm{C}_{2} \mathrm{HF}_{5}$, and $\mathrm{C}_{6} \mathrm{~F}_{12} \mathrm{O}$ (for which kinetic mechanisms were available or developed) was studied through perfectly-stirred reactor (PSR) simulations, which explored lack of kinetic inhibition (at sub-inerting concentrations) by $\mathrm{C}_{2} \mathrm{HF}_{5}$ and $\mathrm{C}_{6} \mathrm{~F}_{12} \mathrm{O}$ in the aerosol can test. In order to understand the overpressure (and insufficient kinetic inhibition) by $\mathrm{C}_{3} \mathrm{H}_{2} \mathrm{~F}_{3} \mathrm{Br}$, the present work extends those analyses by using similar stirred-reactor simulations, but employing a recently-developed kinetic model for $\mathrm{C}_{3} \mathrm{H}_{2} \mathrm{~F}_{3} \mathrm{Br}$ in flames $[9,26]$.

The motivation for the present work is to understand the unwanted overpressure in the FAA-ACT. Nonetheless, the work is more general in that halogenated alkenes are new class of chemical for halon replacement (most previous agents have been fluorinated alkanes). A 
double bond generally increases reactivity with $\mathrm{OH}$ in the troposphere, lowering both the global warming potential (GWP) and ozone depletion potential (ODP), but also increases the flammability, as discussed by Takizawa et al. [27]. The combustion behavior of halogenated hydrocarbon/air systems is also of interest with regard to new, marginally flammable refrigerants [28] (e.g., replacing the $\mathrm{Br}$ with $\mathrm{F}$ in 2-BTP yields the refrigerant HFO 1234yf $\left(\mathrm{CH}_{2} \mathrm{CFCF}_{3}\right)$, a new, low-ODP, low-GWP refrigerant). Finally, clean fire suppressant agents (i.e., halon replacements) used in the presence of added energy from electrical sources [29], or used in situations which might involve significant fuel-air-agent premixing, may have lower effectiveness (or enhanced reactivity), for reasons similar to those pertinent to the FAA-ACT.

\section{FAA Aerosol Can Test Experiment}

The FAA Aerosol Can Test [1] simulates a fire in an aircraft cargo bay container that heats an aerosol can, causing it to burst and fueling an explosion. In the FAA-ACT, a heated container at about 16 bar, releases its contents ( $270 \mathrm{~g}$ ethanol, $90 \mathrm{~g}$ propane, and $90 \mathrm{~g}$ water), as a two-phase impulsive spray via a fast-acting valve. A continuous DC arc across electrodes (6.4 mm gap, shielded from the high-velocity spray) located about $1 \mathrm{~m}$ downstream of the valve ignites the mixture. The fireball expands into the chamber atmosphere of premixed ambient air, water vapor and suppressant. The temperature and pressure in the chamber increase over a time of about $1 \mathrm{~s}$, and in the absence of suppressant, the peak pressure rise is about 2 bar.

During each test, instruments record the pressure, temperature, visual images, and concentrations of agent and oxygen. Unconfined tests without suppressant create a $3.4 \mathrm{~m}$ diameter fire ball [30]. 


\section{Approach}

The maximum peak over-pressures in the FAA-ACT are explored through equilibrium calculations for the reaction mixtures of interest, while any potential kinetic limitations to reaching the peak values are explored via stirred-reactor simulations. Since the experiment involves an impulsively released two-phase turbulent flow of fuel into the oxidizer, it is difficult to know the actual initial mixing conditions for the equilibrium or PSR simulations. Nonetheless, the relevant thermodynamics and kinetics of the system are explored by performing the simulations over the entire range of agent loading and fuel/oxidizer volume ratio (e.g., stoichiometry).

\subsection{Initial Conditions}

The volume fraction of inhibitor in the oxidizer $X_{i n h}$ is a variable, as is the fuel-oxidizer ratio. Because the oxidizer consists of both air and agent (which is also a reactant), the oxidizer is essentially partially premixed (i.e., the agent may act as a fuel). Presentation of the results in terms of a fuel-oxidizer stoichiometric ratio is not practical: as the agent concentration in the oxidizer is increased, $\phi$ for stoichiometric conditions changes due to the agent's oxygen demand, as well as due to changes in the equilibrium products (as the hydrogen-halogen ratio in the flame changes). Hence, the stoichiometry effect is presented in the present work in terms of the fraction $(\eta)$ of the total oxidizer that reacts; that is, $\eta$ is the fraction of the entire test chamber volume that is involved in the reaction with the fixed quantity of fuel species from the aerosol can contents. As discussed below, since stoichiometric reaction of the propane/alcohol/water fuel in the aerosol can test requires about $29 \%$ of the chamber volume 
(with no inhibitor added), $\eta$ is related to the stoichiometry $\phi_{\text {uninhibited }}$ of the system before addition of the 2-BTP, via the relation: $\phi_{\text {uninhibited }}=0.29 / \eta$.

The fuel quantity is taken to be the contents of the aerosol can simulator ( $270 \mathrm{~g}$ ethanol, $90 \mathrm{~g}$ propane, and $90 \mathrm{~g}$ water). The oxidizer consists of ambient air (oxygen, nitrogen, and water vapor) and the premixed suppressant (when present). The relative humidity (RH) of the ambient air is known to have a significant effect on the behavior of HFCs in hydrocarbon flames owing to the sensitivity to the halogen-hydrogen atomic ratio [28, 31, 32]. Relative humidity of the test air was not reported in the FAA tests; however, analysis of local weather data for the days of the tests (the test chamber was filled with approximately ambient outdoor air) indicates that water vapor volume fractions were in the range of 0.005 to 0.01 (corresponding to $20 \%$ to $40 \%$ R.H. at $21^{\circ} \mathrm{C}$ ). Hence, the calculations were performed for a water vapor volume fraction $X_{w v}$ of $0,0.125$, and 0.025 in the $\mathrm{O}_{2} / \mathrm{N}_{2} / \mathrm{H}_{2} \mathrm{O}$ oxidizer mix, corresponding to $0 \%, 50 \%$, and $100 \%$ R.H at $21^{\circ} \mathrm{C}$.

To summarize: the fuel (aerosol can contents) components and their quantities were fixed. The oxidizer components (dry air, $\mathrm{H}_{2} \mathrm{O}$, and agent) were variable, and specified according to their volume fractions (with $X_{\mathrm{N} 2} / X_{\mathrm{O} 2}=3.76$ ); and the total amount of oxidizer was also variable, expressed as $\eta$, the fraction of chamber volume (11400 L) involved in the combustion. The initial inhibitor volume fraction in the oxidizer gases $X_{i n h}$ was varied from $0 \%$ to $6 \%$, for $\mathrm{C}_{3} \mathrm{H}_{2} \mathrm{~F}_{3} \mathrm{Br}$, and $5 \%$ for $\mathrm{CF}_{3} \mathrm{Br}$, corresponding to approximately the maximum amount added in the FAA tests $[1,33]$. The fraction of the chamber volume involved in the combustion, $\eta$, was varied from about 0.17 to 1.00 . Initial pressure and temperature were 1.01 bar and $298 \mathrm{~K}$. 


\subsection{Equilibrium Thermodynamics}

The equilibrium conditions of the aerosol can test were calculated using both the STANJAN-III program of Reynolds [33], and CEA2 of Gordon and McBride [34]; the two codes gave results very close to each other. The calculations were performed over the wide range of initial conditions described above. Constant enthalpy, constant pressure solutions were obtained. The equilibrium simulations were used to predict the combustion temperature of the involved reactants, and the explosion pressure in the FAA test chamber, as described below and in Ref. [6].

\subsection{Kinetic Mechanism}

A kinetic model for hydrocarbon flames inhibited by $\mathrm{C}_{3} \mathrm{H}_{2} \mathrm{~F}_{3} \mathrm{Br}$ (2-BTP) has been developed. The kinetic model consists of four sub-mechanisms: (1) hydrocarbon combustion; (2) fluorocarbon inhibition; (3) bromine-species inhibition; (4) $\mathrm{C}_{3} \mathrm{H}_{2} \mathrm{~F}_{3} \mathrm{Br}$ decomposition. The $\mathrm{C}_{1}-$ $\mathrm{C}_{4}$ model of Wang et al [35] (111 species and 784 reactions ) is used for the hydrocarbon flame. This model has been validated for a wide range of conditions. Added to this are 5 species and 36 reactions related to ethanol combustion, from Dryer and co-workers [36]. The starting mechanism to describe reactions of the hydrofluorocarbons in hydrocarbon flames is the National Institute of Standards and Technology (NIST) HFC mechanism [37], including modifications suggested in more recent work [38, 39], also as summarized in Ref. [7]. In addition, more recent modeling of the combustion of pure fluorocarbon agents [40] suggests that relatively large concentrations of $\mathrm{F}$ atoms are observed in the reaction and post-flame zones. Thus, some formation of $F_{2}$ is expected, and reactions related to its formation and consumption (not previously considered) have now been added. The kinetic model for flame 
inhibition by $\mathrm{C}_{3} \mathrm{H}_{2} \mathrm{~F}_{3} \mathrm{Br}$ is based on a decomposition model developed at NIST [9], that describes the reactions down to $\mathrm{Br}$-containing species of $\mathrm{C}_{2}$ species and smaller. Subsequent reaction of these species are from the kinetic model for $\mathrm{CF}_{3} \mathrm{Br}$ inhibition of hydrocarbon-air flames [9] with more recent modifications. The complete $\mathrm{C}_{3} \mathrm{H}_{2} \mathrm{~F}_{3} \mathrm{Br}$ sub-model includes 96 reactions of $\mathrm{Br}$ containing species, as presented in ref. [9]. Thermodynamic data for most of the $\mathrm{Br}$-containing species are from ref. [9] or Burcat et al. [41], while data for the set of species related to the decomposition of 2-BTP are estimated or calculated, as described in ref. [9]. The complete kinetic model for the simulations with $\mathrm{C}_{3} \mathrm{H}_{2} \mathrm{~F}_{3} \mathrm{Br}$ has 1609 reactions and 188 species, and is available in ref. [9].

As a first step in model validation, the measured and calculated premixed burning velocities have been compared [9]. Since, as discussed in ref. [26], 2-BTP in hydrocarbon flames largely decomposes into the same fragments as does $\mathrm{CF}_{3} \mathrm{Br}$, and since the $\mathrm{CF}_{3} \mathrm{Br}$ mechanism itself was updated, the $\mathrm{CF}_{3} \mathrm{Br}$ sub-mechanism in the 2-BTP mechanism was tested first, by comparing measured and calculated flame inhibition by $\mathrm{CF}_{3} \mathrm{Br}$. Fig. 1 shows the measured [42$45]$ and calculated [26, 46] burning velocity of stoichiometric methane-air flames with added $\mathrm{CF}_{3} \mathrm{Br}$ (using same kinetic mechanism and the SANDIA PREMIX code) [26, 46]. As illustrated, the agreement is excellent, lending confidence in the $\mathrm{CF}_{3} \mathrm{Br}$ sub-mechanism. For 2-BTP, data have recently become available $[45,46]$ on its effect on the measured and calculated burning velocity of $\mathrm{CH}_{4}$ - and $\mathrm{C}_{3} \mathrm{H}_{8}$-air flames. For example, Fig. 2 shows the measured (points) and calculated (lines, again using the same mechanism and the SANDIA PREMIX code [47]) laminar burning velocity for 2-BTP addition to methane air flames of equivalence ratios $(\phi)$ of 1.0 (upper curves) and 0.6 (lower curves), and initial conditions of ambient (solid lines), and slightly 
compressed (dotted lines) reactant gases. As illustrated, the predictive ability of the model is good for these conditions. Of course, while such comparisons are a necessary first step in model validation, more work is required to more thoroughly test and develop the mechanism. Nonetheless, we can proceed to use the mechanism to examine the kinetic behavior of 2-BTP in the FAA-ACT environment.

\subsection{Perfectly-Stirred Reactor Simulations}

PSR simulations were used to understand kinetic limitations associated with the explosion pressure predictions of the equilibrium simulations. Flame extinction caused by suppressants is controlled by the characteristic times for chemical reaction and transport, as described by the Damköhler number $\mathrm{Da}=\tau_{r} / \tau_{c}$, in which $\tau_{r}$ is the flow residence time, and $\tau_{c}$ is the chemical time [48]. Hence, an important step for understanding flame suppression is to estimate the overall reaction rate. Given the explosive, two-phase, turbulent mixing process occurring during release of the aerosol can test simulator fuel [30], the reaction zone might be simulated reasonably well by a PSR. Additionally, the PSR blow-out residence time has been correlated with both the laminar flame speed [49] and extinction of laminar diffusion flames with added inert suppressants [50], indicating its utility as a measure of overall combustion reaction rate. Recently, it has been shown to predict co- and counter-flow diffusion flame extinction conditions, and is suggested as a basis for predicting flame extinguishing in CFD models of large fires [51](i.e., conceptually the approach taken in the present work). To obtain the characteristic chemical time at extinction using a stirred-reactor model [52], the blow-out conditions are determined using the SANDIA PSR program [52], as described previously [7, 50], and the overall chemical rate $\omega_{p s r}$ is the inverse of the chemical time. While any enhanced 
mixing in the FAA-ACT occurring due to turbulence cannot be modeled directly with the PSR simulations, the simulations can bracket the range of mixing conditions that might occur, and quantify the overall reaction rate therein.

\section{Results}

\subsection{Combustion Temperatures}

Fig. 3 (left frame, $\mathrm{C}_{3} \mathrm{H}_{2} \mathrm{~F}_{3} \mathrm{Br}$; right frame, $\mathrm{CF}_{3} \mathrm{Br}$ ) shows the adiabatic combustion temperature, $T_{a d}$, of the involved gases as a function of the fraction $\eta$ of chamber air participating in the reaction with the fuel, with different curves corresponding to different values of $X_{\text {inh }}$. Note that Fig. 3 shows the combustion temperature of the involved gases; for $\eta<$ 1 , the final temperature of all the mixed gases would be lower due to dilution. As a reference, the second $\mathrm{x}$-axis in Fig. 3 provides the fuel-oxidizer ratio in terms of the equivalence ratio $\phi_{\text {uninhibited }}$ of the uninhibited system (i.e., $X_{i n h}=0$ ). As indicated, in the absence of inhibitor $\left(X_{\text {inh }}=0\right)$, the mixture is stoichiometric $\left(\phi_{\text {uninhibited }}=1\right)$ at $\eta=0.29$. In general, for $X_{\text {inh }}=0, \phi_{\text {uninhibited }}=$ $0.29 / \eta$, so the figure shows approximately, the range $\eta$ from 0.27 to 1.0 , or $\phi_{\text {uninhibited }}$ from 1.07 to 0.29 . Although data can be presented in terms of $\phi_{\text {uninhibited }}$ (or even a $\phi$ which includes the oxygen demand of the inhibitor), the fuel-oxidizer ratio is described in the present work using $\eta$ because: 1.) the equivalence ratio loses utility when the oxidizer is partially premixed at varying values of $X_{i n h}, 2$.) the equilibrium products change drastically when more halogen is present than $\mathrm{H}$ atom, which affects the definition of $\phi$, and 3.) $\eta$ has an easily interpreted physical meaning (the fraction of chamber volume of oxidizer reacting with the given fixed fuel mass). 
In Fig. 3 , the shape of the curve for no agent $\left(X_{\text {inh }}=0\right)$ follows the variation in $T_{a d}$ with fuel-air equivalence ratio, and the peak adiabatic flame temperature $T_{a d, p e a k}$ is reached when about one third $(\eta=0.29)$ of the chamber volume of oxidizer reacts with the aerosol can contents. With addition of $\mathrm{CF}_{3} \mathrm{Br}$, Fig. 3 (left frame) shows that added agent reduces $T_{\text {ad,peak }}$ about $100 \mathrm{~K}$ for $\mathrm{X}_{\mathrm{inh}}=0.05$ and the value of $\eta$ at the peak temperature $\eta_{\max }$ is nearly constant at around 0.30. This is also illustrated in Fig. 4 which shows the peak value of the $T_{a d}$ for $\mathrm{CF}_{3} \mathrm{Br}$ (dotted curves), as well as the value of $\eta$ at which the peak occurs ( $\left.\eta_{\max }\right)$. For $\mathrm{CF}_{3} \mathrm{Br}$ addition, the lower $T_{\text {ad,peak }}$ occurs because products of $\mathrm{CF}_{3} \mathrm{Br}$ reaction have a higher heat capacity for the available heat release from its reaction (relative to reaction of the fuel).

With addition of $\mathrm{C}_{3} \mathrm{H}_{2} \mathrm{~F}_{3} \mathrm{Br}$ (right frame of Fig. 3), the $T_{\text {ad,peak }}$ remains nearly constant at around $2160 \mathrm{~K}$, although the value of $\eta$ required to achieve the peak $T_{a d}, \eta_{\max }$, increases. Fig. 4 shows the peak value of the $T_{a d}$ for $\mathrm{C}_{3} \mathrm{H}_{2} \mathrm{~F}_{3} \mathrm{Br}$, as well as the value of $\eta$ at which the peak occurs $\left(\eta_{\text {maxt }}\right)$. For $\mathrm{C}_{3} \mathrm{H}_{2} \mathrm{~F}_{3} \mathrm{Br}, \eta_{\max }$ increases with agent addition both due to agent dilution of the $\mathrm{O}_{2}$ in the air, and due to the oxygen demand of the $\mathrm{C}_{3} \mathrm{H}_{2} \mathrm{~F}_{3} \mathrm{Br}$ itself. Indeed, Fig. 4 shows that at $X_{\text {inh }}=5.3 \%, \eta_{\max }=1.0$ so that all of the chamber volume is required to achieve peak $T_{a d}$. The fuel effect of $\mathrm{C}_{3} \mathrm{H}_{2} \mathrm{~F}_{3} \mathrm{Br}$ is also illustrated by considering added agent at fixed values of $\eta$ : at $\eta=0.29$, adding agent always reduces $T_{a d}$; whereas for $\eta \geq 0.30$, (lean conditions with respect to the fuel in the aerosol can), adding agent first increases $T_{a d}$, then lowers it at high enough $X_{\text {inh. }}$ An important feature of the $T_{a d}$ curve for $\mathrm{C}_{3} \mathrm{H}_{2} \mathrm{~F}_{3} \mathrm{Br}$ in Fig. 3 is that at higher values of $X_{\text {inh, }}$, the curves become very flat, so that large changes in $\eta$ have a small effect on $T_{a d}$. 
The near-constant value of $\eta_{\max }$ occurs because for $\mathrm{CF}_{3} \mathrm{Br}$ addition (at low volume fraction), there is no additional oxygen demand to consume that agent. That is, it is a unique feature of $\mathrm{CF}_{3} \mathrm{Br}$ that that left-over water vapor from oxidation of the hydrocarbon fuel provides sufficient $\mathrm{H}$ and $\mathrm{O}$ atoms to oxidize the agent to the most stable products $\mathrm{CO}_{2}, \mathrm{HBr}$, and $\mathrm{HF}\left(2 \mathrm{H}_{2} \mathrm{O}+\mathrm{CF}_{3} \mathrm{Br}=>\mathrm{CO}_{2}+3 \mathrm{HF}+\mathrm{HBr}, T_{a d}=985 \mathrm{~K}\right)$, explaining both the constant value of $\eta_{\max }$ and lower $T_{a d}$ with $\mathrm{CF}_{3} \mathrm{Br}$ addition. This feature is generally true for any suppressant $\mathrm{CX}_{4}$ ( $\mathrm{X}$ is any halogen), but only if the agent is added at a concentration less than that for which there are more hydrogen atoms $\mathrm{H}$ than fluorine $\mathrm{F}$ (which is nearly always the case for $\mathrm{CF}_{3} \mathrm{Br}$ addition because it puts flames out at values of $X_{\text {inh }}$ less than those for unity $[\mathrm{F}] /[\mathrm{H}]$ ratio).

Because the $[\mathrm{H}] /[\mathrm{F}]$ ratio in the system can affect the equilibrium products, and because the water vapor content can vary, the equilibrium calculations were performed for a range of relative humidity. For $\mathrm{C}_{3} \mathrm{H}_{2} \mathrm{~F}_{3} \mathrm{Br}$, the effects were significant: increasing humidity from $0 \% \mathrm{RH}$ to $50 \% \mathrm{RH}$ can increase $T_{a d}$ up to about $10 \%$, but it depends upon the $[\mathrm{F}] /[\mathrm{H}]$ ratio in the flame, as discussed in ref. [32]. Hence, the high water content of the FAA-ACT fuel may be influencing the behavior.

\subsection{Explosion Pressure Rise}

Based on equilibrium calculations, it is possible to estimate the pressure rise in the FAAACT test chamber $[6,53]$. For a given inhibitor loading $X_{i n h}$, a value of $\eta$ is selected, and an equilibrium calculation gives the conditions of the products; these are allowed to mix adiabatically with the remaining fraction (1- $\eta$ ) of chamber oxidizer gas, which is treated as inert. The pressure rise is calculated over the entire range of $\eta$ and $X_{\text {inh }}$; however, to estimate 
the expected explosion pressure rise at a given agent loading, it is necessary to estimate the actual value of $\eta$ pertinent to each FAA test (of a given value of $X_{\text {inh }}$ ). In previous work [7] it was argued that the amount of involved oxidizer can be controlled by either the turbulent mixing resulting from the impulsive release of the aerosol can simulator contents, or by diffusion. It was shown in previous work analyzing the FAA-ACT results, that assuming stoichiometric proportions of reactants (as in a diffusion flame), i.e., by selecting $\eta$ that gives the peak temperature predicted the pressure rise very well. This was found to be true for the agents HFC-125 $\left(\mathrm{C}_{2} \mathrm{HF}_{5}\right)$ and Novec $1230\left(\mathrm{C}_{6} \mathrm{~F}_{12} \mathrm{O}\right)$, and hence, the same approach for estimating $\eta$ is applied here.

Fig. 5 shows the predicted pressure rise for $\mathrm{C}_{3} \mathrm{H}_{2} \mathrm{~F}_{3} \mathrm{Br}$ and $\mathrm{CF}_{3} \mathrm{Br}$ in the FAA-ACT (FAA experimental results: solid circles; predicted values: lines). For $\mathrm{CF}_{3} \mathrm{Br}$, the predicted pressure rise is nearly constant. This is expected based on the results for $T_{a d}$ described above: both $T_{\text {ad,peak }}$ and $\eta_{\text {maxt }}$ are nearly constant with $\mathrm{CF}_{3} \mathrm{Br}$ addition, so both the mass of reactants (controlled by $\eta$ ) and the expansion ratio of the gases (controlled by $T_{a d, p e a k}$ ) is constant, leading to a constant pressure rise for all values of $X_{i n h}$. Nonetheless, the experimental pressure rise decreases with $\mathrm{CF}_{3} \mathrm{Br}$ addition, so that the equilibrium model does not predict the pressure rise well. As will be described below, for $\mathrm{CF}_{3} \mathrm{Br}$, the overall rate is always reduced with agent addition, and hence kinetic limitations prevent the system from achieving equilibrium conditions with added $\mathrm{CF}_{3} \mathrm{Br}$. In contrast, with added $\mathrm{C}_{3} \mathrm{H}_{2} \mathrm{~F}_{3} \mathrm{Br}$ the pressure rise increases rapidly, primarily due to the increase in $\eta_{\max }$ (since $T_{\text {ad,peak }}$ is maintained high). The agreement between the FAA-ACT experimental results and the predicted pressure rise (based on equilibrium thermodynamics) for $\mathrm{C}_{3} \mathrm{H}_{2} \mathrm{~F}_{3} \mathrm{Br}$ is excellent considering the simplifications in the 
model. Similarly, in previous work, the pressure rise with $\mathrm{C}_{2} \mathrm{HF}_{5}$ [7] or $\mathrm{C}_{6} \mathrm{~F}_{12} \mathrm{O}$ [8] addition was also predicted well. For $\mathrm{C}_{3} \mathrm{H}_{2} \mathrm{~F}_{3} \mathrm{Br}$, the experimental pressure rise at $X_{i n h}=3 \%$ is somewhat underpredicted. While water vapor can have some effect (as shown by the three curves in Fig. 5 for $0 \%, 50 \%$, and $100 \%$ R.H.), variation in the predicted $\eta_{\max }$ due to the peak temperature criterion can have a much larger effect. For example, at $3 \% \mathrm{C}_{3} \mathrm{H}_{2} \mathrm{~F}_{3} \mathrm{Br}$, Fig. 3 shows that values of $T_{a d}$ near $T_{a d, p e a k}$ vary only mildly with $\eta$. For $T_{a d}$ within $2 \%(43 \mathrm{~K})$ of the peak value $(2162 \mathrm{~K})$, $\eta_{\max }$ varies from about 0.41 to 0.58 , which results in a predicted pressure rise ranging from 2.9 bar to 3.9 bar. This variation is about the same as the discrepancy between the experiment and prediction in Fig. 5. Furthermore, the impulsive release of the fuel in the FAA-ACT is somewhat stochastic, and repeated tests at $3 \% \mathrm{C}_{3} \mathrm{H}_{2} \mathrm{~F}_{3} \mathrm{Br}$ would be expected to have relatively large uncertainties, as shown in other tests in the FAA-ACT [54].

The equilibrium calculations used to estimate the pressure rise shown in Fig. 5 are based on the assumption of complete reaction to equilibrium products. Nonetheless, kinetic limitations do not influence the pressure rise of the system even for $\mathrm{C}_{3} \mathrm{H}_{2} \mathrm{~F}_{3} \mathrm{Br}$ volume fraction up to $6 \%$, whereas they affected the $\mathrm{CF}_{3} \mathrm{Br}$ results at all agent loadings. This is somewhat surprising, since as described above, cup-burner and other tests showed similar performance for $\mathrm{CF}_{3} \mathrm{Br}$ and $\mathrm{C}_{3} \mathrm{H}_{2} \mathrm{~F}_{3} \mathrm{Br}$. To understand the small effect of $\mathrm{C}_{3} \mathrm{H}_{2} \mathrm{~F}_{3} \mathrm{Br}$ on the overall reaction rate leading to the pressure rise in the FAA-ACT chemical system, as compared to the large effect of $\mathrm{CF}_{3} \mathrm{Br}$, PSR simulations were performed, as described below.

\subsection{Perfectly-Stirred Reactor Calculations}

$\underline{\mathrm{CF}}_{3} \underline{\mathrm{Br} \text { or }} \mathrm{C}_{3} \mathrm{H}_{2} \mathrm{~F}_{3} \mathrm{Br}$ 
For the FAA-ACT, Fig. 6 shows (left frame: $\mathrm{CF}_{3} \mathrm{Br}$, right frame: $\mathrm{C}_{3} \mathrm{H}_{2} \mathrm{~F}_{3} \mathrm{Br}$ ), the characteristic overall reaction rate in the PSR, $\omega_{p s r}$, as a function of $\eta$ (different curves in each figure refer to different values of $\left.X_{i n h} ;\right)$. The results for $X_{i n h}=0$ show that with no agent, $\omega_{p s r}$ is very sensitive to $\eta$ (i.e., the stoichiometry). This mimics the well-known sensitivity of the laminar burning velocity to stoichiometry. For $\mathrm{CF}_{3} \mathrm{Br}$ addition (left frame), the overall reaction rate decreases rather uniformly for all values of $\eta$, although the decrease in $\omega_{p s r}$ with added $\mathrm{CF}_{3} \mathrm{Br}$ is greater for the leaner flames (higher $\eta$ ). Moreover, the value of $\eta$ for peak temperature $\left(\eta_{\max }\right)$ is relatively constant). In contrast, for addition of $\mathrm{C}_{3} \mathrm{H}_{2} \mathrm{~F}_{3} \mathrm{Br}$ (right frame), value of $\eta_{\max }$ increases as $X_{\text {inh }}$ increases, and at high agent loading, the curves flatten out near $\eta_{\max }$. For example, with $5 \% \mathrm{C}_{3} \mathrm{H}_{2} \mathrm{~F}_{3} \mathrm{Br}$, the reactivity of the system is nearly constant for $0.5 \leq \eta \leq 1.0$. This is because at high $\eta$, the mixture is more like a premixed $\mathrm{C}_{3} \mathrm{H}_{2} \mathrm{~F}_{3} \mathrm{Br}$-air system for which the effective stoichiometry would be independent of $\eta$. , than it is like a flame of the aerosol can test fuel and air. For rich flames $(\eta<0.29), C_{3} \mathrm{H}_{2} \mathrm{~F}_{3} \mathrm{Br}$ actually works better than $\mathrm{CF}_{3} \mathrm{Br}$. As discussed in ref. [46], adding $\mathrm{C}_{3} \mathrm{H}_{2} \mathrm{~F}_{3} \mathrm{Br}$ to flames makes them richer, so that the chainbranching radicals are reduced by both the hydrocarbon inhibition $[55,56]$ and the catalytic bromine cycle.

The lower explosion pressure in the FAA-ACT with added $\mathrm{CF}_{3} \mathrm{Br}$ at all volume fractions (as illustrated by the points and horizontal line for $\mathrm{CF}_{3} \mathrm{Br}$ in Fig. 5) is a result of the constant value of $\eta_{\max }$ shown in Fig. 5 and reduced overall kinetic rate (at all values of $\eta$ ) shown in Fig. 6. In contrast, $\mathrm{C}_{3} \mathrm{H}_{2} \mathrm{~F}_{3} \mathrm{Br}$ addition increases $\eta_{\operatorname{maxT}}$, and its effect on the overall reaction rate $\omega_{p s r}$ depends upon $X_{i n h}$ and the value of $\eta$. As will be shown below, lean fuel-air mixtures become 
more flammable with the addition of $\mathrm{C}_{3} \mathrm{H}_{2} \mathrm{~F}_{3} \mathrm{Br}$, which together with the increasing value of $\eta$ with agent addition, leads to the increased explosion pressure.

As shown in Fig. 6, for $\mathrm{C}_{3} \mathrm{H}_{2} \mathrm{~F}_{3} \mathrm{Br}$, the effect of $X_{\text {inh }}$ on $\omega_{p s r}$ is dependent upon the value of $\eta$. For $\eta \leq 0.5$, (richer conditions), adding inhibitor always lowers $\omega_{p s r}$; whereas for $\eta=>0.5$, (leaner conditions), increasing $X_{i n h}$ first raises the $\omega_{p s r}$, and then lowers $\omega_{p s r}$ at higher $X_{i n h}$. In other words, for leaner flames (higher $\eta$ ) adding inhibitor can increase the overall reaction rate in the system, rather than decrease it as would be expected for a fire suppressant. The influence of increasing temperature with added agent (shown in Fig. 3) overrides the inhibition effect due to $\mathrm{H}$-atom scavenging by brominated and fluorinated species. Moreover, added inhibitor above $X_{i n h}=4 \%$ has a diminished effect on $\omega_{p s r}$ (i.e., the curves are close to each other at high $\eta$ and high $\left.X_{i n h}\right)$. That is, at low inhibitor loadings and over-ventilated conditions, adding agent makes the system more reactive, and at higher loadings, higher concentrations have less effect on the reactivity. Both effects can explain the lack of effective inhibition with added $\mathrm{C}_{3} \mathrm{H}_{2} \mathrm{~F}_{3} \mathrm{Br}$ in the FAA-ACT. As discussed previously [26], while the bromine-catalyzed radical recombination cycle is still active with $\mathrm{C}_{3} \mathrm{H}_{2} \mathrm{~F}_{3} \mathrm{Br}$, the cycle is not as effective at higher temperatures, and the increased temperature caused by agent reaction increases the equilibrium radical concentrations. The net effect of these features is that radical concentrations, and hence the burning velocity, are not as well reduced with $\mathrm{C}_{3} \mathrm{H}_{2} \mathrm{~F}_{3} \mathrm{Br}$ addition as with $\mathrm{CF}_{3} \mathrm{Br}$ addition.

As described above, water vapor has been found to: 1.) have a large effect on the flammability limits of marginally flammable refrigerants [28] and 2.) increase the calculated burning velocity of flames of preheated $\mathrm{C}_{3} \mathrm{H}_{2} \mathrm{~F}_{3} \mathrm{Br}$-air mixture [26]; hence it is of interest to 
determine if it has the same effect here (especially since the FAA-ACT has a large water content in the base fuel). PSR simulations for different humidity levels show that increasing the RH from $0 \%$ to $50 \%$ can either increase or decrease the reactivity of the system, by up to a factor of two, depending upon the values of $\eta$ and $X_{i n h}$. This effect is due to variations in the hydrogenhalogen ratio in the reactants (which varies with $X_{\text {inh }}$ and $\eta$ ), as has been discussed in ref. [32] with respect to $\mathrm{C}_{2} \mathrm{HF}_{5}$ flame inhibition.

Using Fig. 6, it is instructive to compare the reduction in $\omega_{p s r}$ caused by addition of $\mathrm{CF}_{3} \mathrm{Br}$ to that of $\mathrm{C}_{3} \mathrm{H}_{2} \mathrm{~F}_{3} \mathrm{Br}$. For the uninhibitied flames $\left(X_{\text {inh }}=0\right)$, the peak reaction rate is $\omega_{p s r}=9000 \mathrm{~s}^{-1}$. For a flame that is stoichiometric before addition of agent $(\eta=0.29)$, to which $\mathrm{CF}_{3} \mathrm{Br}$ is added, the FAA-ACT was inerted with $X_{i n h} \approx 3.5 \%$, at which $\omega_{p s r}=1800 \mathrm{~s}^{-1}$; whereas for $\mathrm{C}_{3} \mathrm{H}_{2} \mathrm{~F}_{3} \mathrm{Br}$ (still holding $\eta$ constant at 0.29 ) at $X_{\text {inh }}=0.06$ (the maximum added in the FAA tests) leads to $\omega_{p s r}=20$ $s^{-1}$. That is, for $\eta=0.29, C_{3} \mathrm{H}_{2} \mathrm{~F}_{3} \mathrm{Br}$ should work much better than $\mathrm{CF}_{3} \mathrm{Br}$. Nonetheless, to compare the performance of the two agents in the FAA-ACT, we need to know the actual value of $\eta$ (i.e., the fuel/oxidizer mixing) at which the system is operating. For $\mathrm{C}_{3} \mathrm{H}_{2} \mathrm{~F}_{3} \mathrm{Br}$, as discussed above, the value of $\eta$ relevant to the FAA-ACT experiments can be estimated from the experimental explosion pressure, using the equilibrium calculations that predicted the pressure rise (i.e., the curve for $\eta_{\max }$ vs. $X_{\text {inh }}$ for $\mathrm{C}_{3} \mathrm{H}_{2} \mathrm{~F}_{3} \mathrm{Br}$ in Fig. 4). Those values of $\eta$ required to produce the $T_{a d, \max }$ (i.e., $\eta_{\max T}$ ) for a given value of $X_{\text {inh }}$ are indicated by the green circles on each curve for $X_{\text {inh }}$ in Fig. 6 (for $\mathrm{C}_{3} \mathrm{H}_{2} \mathrm{~F}_{3} \mathrm{Br}$ only). That is, based on the experimental pressure rise, the green circles illustrate (globally) the state of mixing (reaction stoichiometry) of the system with $\mathrm{C}_{3} \mathrm{H}_{2} \mathrm{~F}_{3} \mathrm{Br}$ addition, as well as the overall reaction rate that would be expected at that value of $\eta$. As illustrated by the green circles in Fig. 6 (and the right-hand scale of Fig. 4, from which the 
gren circles came), the value of $\eta_{\max }$ increases with $X_{\text {inh }}$, and the overall chemical rate decreases.

In contrast, for $\mathrm{CF}_{3} \mathrm{Br}$, no information on $\eta$ can be extracted from a comparison of predicted and measured pressure rise in the FAA-ACT. Referring to Fig. 5, the line representing the pressure rise vs. $X_{\text {inh }}$ for $\mathrm{CF}_{3} \mathrm{Br}$ (i.e., the horizontal line) shows that the pressure rise is predicted to be constant for all $X_{i n h}<0.07$. As discussed previously [6], the reason that $\mathrm{CF}_{3} \mathrm{Br}$ does not show this effect is due to the unique stoichiometry of this agent in hydrocarbon systems. Since the value of $X_{\text {inh }}$ is low, the ratio of total fluorine atoms to hydrogen atoms $[\mathrm{F}] /[\mathrm{H}]$ is always $<1$ for $\mathrm{CF}_{3} \mathrm{Br}$ in the FAA aerosol can test. Hence, water exists as a product of combustion, and there are always sufficient $\mathrm{H}$ and $\mathrm{O}$ molecules left over from the hydrocarbon oxidation (ordinarily in the form of $\mathrm{H}_{2} \mathrm{O}$ ), to supply the $\mathrm{H}$ and $\mathrm{O}$ necessary to oxidize the $\mathrm{CF}_{3} \mathrm{Br}$. A global reaction (exothermic) representing this is: $\mathrm{CF}_{3} \mathrm{Br}+2 \mathrm{H}_{2} \mathrm{O}=>\mathrm{CO}_{2}+3 \mathrm{HF}+\mathrm{HBr}$ (note that $\mathrm{HF}$ is a more stable product for $\mathrm{H}$ atoms than $\mathrm{H}_{2} \mathrm{O}$ ). The end result is that the FAA-ACT, $[\mathrm{F}] /[\mathrm{H}]=1$ occurs at $X_{i n h}=0.11$, and inerting of the chamber occurs at about $X_{i n h}=0.035$, so that there never an added oxygen demand from $\mathrm{CF}_{3} \mathrm{Br}$ addition, and $\eta$ and the pressure rise do not increase as $X_{\text {inh }}$ increases. Hence, no information on $\eta$ can be extracted from the observed pressure rise. Fortunately, there were additional tests done at the FAA which can be used to understand the global mixing of the reactants for the suppressed explosions with added $\mathrm{CF}_{3} \mathrm{Br}$ - and hence, the value of $\eta$ for $\mathrm{CF}_{3} \mathrm{Br}$ addition.

\section{$\underline{\mathrm{CF}_{3}} \underline{\mathrm{Br} / \mathrm{N}_{2}} \underline{\text { Blends }}$}

In order to assess the value of added nitrogen to the reduction in $\mathrm{CF}_{3} \mathrm{Br}$ required to suppress the FAA-ACT explosion, Reinhardt conducted a large series of tests with $\mathrm{CF}_{3} \mathrm{Br} / \mathrm{N}_{2}$ blends [54]. 
Various concentrations of $\mathrm{N}_{2}$ and $\mathrm{CF}_{3} \mathrm{Br}$ were premixed with the air in the chamber, the fastacting valve released the fuel mixture, which sprayed across the high-voltage igniter, and the chamber pressure was measured. These data can also be used to assess the value of $\eta$ relevant to the FAA-ACT for these mixtures. Reinhardt reported the final explosion pressure rise as a function of the concentrations of $\mathrm{CF}_{3} \mathrm{Br}$ and $\mathrm{N}_{2}$ premixed in the chamber. Their data have been replotted in Fig. 7, which shows the measured final explosion pressure rise (in psi for each data point) for the different values of $\mathrm{X}_{\mathrm{CF}_{3} \mathrm{Br}}$ and $\mathrm{X}_{\mathrm{O}_{2}}$ in the chamber. In Fig. 7, the line drawn through the data provides the locus of points separating the explosive mixtures from the non-explosive ones. The significance of these data are that for these mixtures $\left(\mathrm{O}_{2}\right.$ volume fractions \% of: 21 , $20,19,18,17,16$ and 15 , with corresponding $\mathrm{CF}_{3} \mathrm{Br}$ volume fractions of: $3.5,2.8,2.2,1.6,1.0$, 0.5, and 0.0), the system is inerted. Hence, if we do a PSR simulation for each one of these mixtures, over a range of fuel-air stoichiometry (i.e., $\eta$ ), the curves for all the mixtures may intersect at one characteristic value of the overall reaction rate (corresponding to extinction condition for this particular flame configuration and fuel), and one characteristic value of $\eta$ (corresponding to the fuel-oxidizer mixing controlled by the impulsive release of the fuel into the chamber).

Fig. 8 shows the results of the PSR simulations for the $\mathrm{CF}_{3} \mathrm{Br} / \mathrm{N}_{2}$ mixtures. The curves are analogous to the curve in the left frame of Fig. 6 with added $\mathrm{CF}_{3} \mathrm{Br}$ (at $3.5 \%$, which is the inerting value for pure $\mathrm{CF}_{3} \mathrm{Br}$ ), except that the additional curves in Fig. 8 are the inerting conditions for $\mathrm{CF}_{3} \mathrm{Br}$ with added $\mathrm{N}_{2}$, at various ratios. The curves in Fig. 8 intersect at $\omega_{p s r} \approx$ $1700 \mathrm{~s}^{-1}$ and $\eta=0.335$. These numbers imply that for inerting the turbulent reactant mixture from the impulsive release of the alcohol/propane/water fuel of the FAA-ACT, the overall 
reaction rate must be lowered from the uninhibited value of about $9000 \mathrm{~s}^{-1}$, to a value of about $1700 \mathrm{~s}^{-1}$, and that the characteristic mixing of the impulsive release involves about one third of the chamber volume of oxidizer. These are useful numbers, but create a dilemma in interpreting the results for $\mathrm{CF}_{3} \mathrm{Br}$ and $\mathrm{C}_{3} \mathrm{H}_{2} \mathrm{~F}_{3} \mathrm{Br}$. Referring back to Fig. 6 , it can be seen that for pure $\mathrm{CF}_{3} \mathrm{Br}$ (left frame) added at $X_{\text {inh }}=0.035, \eta=0.335$ implies that $\omega_{p s r}=1700 \mathrm{~s}^{-1}$ (as in Fig. 8); however, with $\mathrm{C}_{3} \mathrm{H}_{2} \mathrm{~F}_{3} \mathrm{Br}$ (right frame) added at $X_{\text {inh }}=6 \%, \omega_{\text {psr }}$ is lower than $1700 \mathrm{~s}^{-1}$ for all values of $\eta$. Moreover, at the value of $\eta$ required to give the observed pressure rise (the $X_{\text {inh }}=0.06$ curve at $\eta=1.0), \omega_{p s r}=160 \mathrm{~s}^{-1}$, so that the overall reaction rate is an order of magnitude lower than was required to extinguish the flames with added $\mathrm{CF}_{3} \mathrm{Br} / \mathrm{N}_{2}$ mixtures-yet the flame does not extinguish with $6 \% \mathrm{C}_{3} \mathrm{H}_{2} \mathrm{~F}_{3} \mathrm{Br}$. In the right frame of Fig. $6, \omega_{p s r}$ at $X_{\text {inh }}=0.06$ is indicated by the circle, while in Fig. 5, the experimental pressure rise in the FAA-ACT with $X_{\text {inh }}=0.06$ is indicated by the data point at that value. Insight into the reasons for this can be obtained by examining the extinguishing concentrations for the agents $\mathrm{C}_{2} \mathrm{HF}_{5}$ and $\mathrm{C}_{6} \mathrm{~F}_{12} \mathrm{O}$.

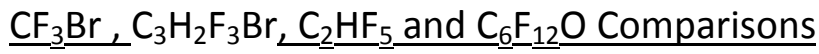

From the data obtained from the FAA experiments, the agent volume fraction in the oxidizer required for inertion of the FAA-ACT was $13.5 \%$ for $\mathrm{C}_{2} \mathrm{HF}_{5}$ [1] and $8.1 \%$ for $\mathrm{C}_{6} \mathrm{~F}_{12} \mathrm{O}$ [3]. The PSR overall reaction rate of these mixtures, as a function of $\eta$, have been calculated in previous work $[7,8]$, and the curves for $\mathrm{X}_{\mathrm{C}_{2} \mathrm{HF}_{5}}=0.133$ and $\mathrm{X}_{\mathrm{C}_{6} \mathrm{~F}_{12}}=0.081$ are shown in Fig. 9 (together with the data for uninhibited reactants, $X_{\text {inh }}=0$, and the $\mathrm{CF}_{3} \mathrm{Br} / \mathrm{N}_{2}$ blends from Fig. 8). As Fig. 9 shows, inerting the FAA-ACT required adding $\mathrm{C}_{2} \mathrm{HF}_{5}$ or $\mathrm{C}_{6} \mathrm{~F}_{12} \mathrm{O}$ such that $\omega_{p s r}$ was lowered to $22 \mathrm{~s}^{-1}$ and $16 \mathrm{~s}^{-1}$, respectively (at $\eta=1.0$, where these systems are operating based on the pressure rise predictions discussed in ref. [1] and [3]). Thus, the characteristic overall 
reaction rate for inertion of the $\mathrm{FAA}-\mathrm{ACT}$ by $\mathrm{C}_{2} \mathrm{HF}_{5}$ or $\mathrm{C}_{6} \mathrm{~F}_{12} \mathrm{O}$ (about $20 \mathrm{~s}^{-1}$ ) is about a factor of 450 lower than the uninhibited flames; whereas, the $\mathrm{CF}_{3} \mathrm{Br} / \mathrm{N}_{2}$ blends only had to reduce overall reaction rate to about $1700 \mathrm{~s}^{-1}$, or about a factor of 53 lower. Hence, it appears that the reactive agents $\mathrm{C}_{2} \mathrm{HF}_{5}$ and $\mathrm{C}_{6} \mathrm{~F}_{12} \mathrm{O}$ have a much more difficult flame to extinguish than the $\mathrm{CF}_{3} \mathrm{Br} / \mathrm{N}_{2}$ mixtures. The reasons for this can be explained by the reactivity of the pure $\mathrm{C}_{2} \mathrm{HF}_{5}$-air and $\mathrm{C}_{6} \mathrm{~F}_{12} \mathrm{O}$-air systems, and the effect of strain on the extinguishing concentrations of fire suppressants.

It is well known, from previous work, that the concentration of a fire suppressant agent required for extinction depends upon the strain rate of the flame to be extinguished. For example, Fig. 10 [57] shows the volume fraction of a suppressant required to extinguish a methane-air counterflow diffusion flame as a function of the strain rate. As indicated, for $\mathrm{C}_{2} \mathrm{HF}_{5}, \mathrm{CF}_{3} \mathrm{CHCl}_{2}, \mathrm{C}_{3} \mathrm{H}_{2} \mathrm{~F}_{3} \mathrm{Br}$, or $\mathrm{CF}_{3} \mathrm{Br}$, the required concentration is much lower at high strain.

As discussed by Babushok et al. [40], it is also becoming apparent that some fire suppressants, at slightly elevated temperatures, may have measurable burning velocities. For example, Table 1 shows the calculated burning velocity of some suppressant air mixtures at stoichiometric conditions in air. As indicated, at the typical initial temperature due to compressive heating in the FAA-ACT when there is reaction $\left(460{ }^{\circ} \mathrm{C}\right.$ to $\left.520{ }^{\circ} \mathrm{C}\right)$ [57], the agents $\mathrm{C}_{2} \mathrm{HF}_{5}, \mathrm{C}_{3} \mathrm{H}_{2} \mathrm{~F}_{3} \mathrm{Br}$, and $\mathrm{C}_{6} \mathrm{~F}_{12} \mathrm{O}$ have estimated burning velocities on the order of $1 \mathrm{~cm} / \mathrm{s}$ (note that burning velocities in this range have been measured for similar compounds; e.g., $1.2 \mathrm{~cm} / \mathrm{s}$ for $\mathrm{CH}_{2} \mathrm{CFCF}_{3}$-air mixtures at $298 \mathrm{~K}$ [27]). Moreover, calculations of the premixed laminar burning velocity for mixtures in the FAA-ACT at the inerting point shown in Fig. 9 for $\mathrm{C}_{2} \mathrm{HF}_{5}$ and $\mathrm{C}_{6} \mathrm{~F}_{12} \mathrm{O}$ indicate values of about $1.0 \mathrm{~cm} / \mathrm{s}$ and $1.0 \mathrm{~cm} / \mathrm{s}$, respectively. In contrast, the agent $\mathrm{CF}_{3} \mathrm{Br}$ in air 
is very much less flammable. For example, at the stoichiometric loading $\left(X_{\text {inh }}=0.65\right)$ in pure oxygen, with the reactants preheated to $500{ }^{\circ} \mathrm{C}, \mathrm{CF}_{3} \mathrm{Br}-\mathrm{O}_{2}$ mixtures have a calculated burning velocity of only $0.27 \mathrm{~cm} / \mathrm{s}$. Hence, the burning velocity of $\mathrm{CF}_{3} \mathrm{Br}$-air mixtures at $298 \mathrm{~K}$, and $X_{\text {inh }}=0.035$ is expected to be exceedingly small. The agents $\mathrm{C}_{2} \mathrm{HF}_{5}$ and $\mathrm{C}_{6} \mathrm{~F}_{12} \mathrm{O}$ required the overall reaction rate in the $\mathrm{FAA}-\mathrm{ACT}$ to be lowered much more than $\mathrm{CF}_{3} \mathrm{Br}$ for two reasons. First, the suppressants themselves, at concentrations just below the inerting concentration, can support flames. Second, since they flood the compartment, there can be regions of very low strain, away from the main, high-strain fire to be extinguished. Thus, in regions far away from the impulsive release of the fuel, the strain will be low, and these weak flames can exist. Additional agent is thus required to extinguish the low-strain regions (created by reaction of the suppressant itself). This prediction is consistent with video images of the experiments in the FAA-ACT test chamber with the halon replacements, in which weak flames far from the fuel jet waft around for about $1 \mathrm{~s}$ after the explosive fuel release. These tests in the FAA-ACT have uncovered a new phenomenon which may be of interest to the fire suppression industry: fire suppressants which can effectively extinguish flames at high strain, might themselves contribute to the heat release (and over-pressure) if they are almost (or slightly) flammable on their own, because they can create low-strain regions which are much harder to extinguish than the primary fire being suppressed.

With these results in mind, it is much easier to interpret the behavior of $\mathrm{C}_{3} \mathrm{H}_{2} \mathrm{~F}_{3} \mathrm{Br}$ in the FAA-ACT, as compared to $\mathrm{CF}_{3} \mathrm{Br}$. Referring to Fig. 9, the dotted line marked $\mathrm{C}_{3} \mathrm{H}_{2} \mathrm{~F}_{3} \mathrm{Br}$ represents the overall reaction rate of the system $\omega_{p s r}$ with 2 -BTP added at $X_{\text {inh }}=0.06$ (note that this concentration of agent did not inert the explosion). The solid point on that line at $\eta=1$ 
represents the condition $\eta_{\max }$ (which reproduces the experimental pressure rise). Thus, the overall rate with $\mathrm{C}_{3} \mathrm{H}_{2} \mathrm{~F}_{3} \mathrm{Br}$ added at $6 \%$ is about $160 \mathrm{~s}^{-1}$, or about an order of magnitude faster than the rate $\left(20 \mathrm{~s}^{-1}\right)$ that was required for the agents $\mathrm{C}_{2} \mathrm{HF}_{5}$ and $\mathrm{C}_{6} \mathrm{~F}_{12} \mathrm{O}$ to inert the explosion. Hence, for the low-strain regions caused by reaction of $\mathrm{C}_{3} \mathrm{H}_{2} \mathrm{~F}_{3} \mathrm{Br}$ itself, it does not slow the reaction rate enough to inert the explosion. This is probably because, as illustrated in the right frame of Fig. 3 for $\mathrm{C}_{3} \mathrm{H}_{2} \mathrm{~F}_{3} \mathrm{Br}$, the temperature of the system is still very high $(2154 \mathrm{~K})$ at $X_{\text {inh }}=0.06$; and, as discussed by Babushok et al. [26] (in regard to premixed methane-air flames with added $\mathrm{C}_{3} \mathrm{H}_{2} \mathrm{~F}_{3} \mathrm{Br}$ ), while the catalytic cycle of $\mathrm{Br}$ to recombine the chain-carrying radicals $\mathrm{H}$, $\mathrm{O}$, and $\mathrm{OH}$ still works at high temperature, the equilibrium radical concentrations are high, so the catalytic cycle only drives the radicals to their [high] equilibrium values, and the overall reaction rate remains robust.

\section{Conclusions}

The unusual combustion enhancement observed in the FAA Aerosol Can Test experiments with the fire suppressant $\mathrm{C}_{3} \mathrm{H}_{2} \mathrm{~F}_{3} \mathrm{Br}$ has been studied. A kinetic model for the behavior of $\mathrm{C}_{3} \mathrm{H}_{2} \mathrm{~F}_{3} \mathrm{Br}$ in hydrocarbon flames has been applied to the FAA-ACT via PSR simulations, and the mechanisms of combustion enhancement have been suggested.

The reasons for the large overpressure with $\mathrm{C}_{3} \mathrm{H}_{2} \mathrm{~F}_{3} \mathrm{Br}$ are that with addition of $\mathrm{C}_{3} \mathrm{H}_{2} \mathrm{~F}_{3} \mathrm{Br}$, $T_{a d}$ is nearly constant and high $(2166 \mathrm{~K})$, and due to its fuel-like properties, the fraction of chamber $\eta_{\max }$ required for fuel and agent consumption increases rapidly as $X_{\text {inh }}$ increases. 
Thus, at the highest concentrations of $\mathrm{C}_{3} \mathrm{H}_{2} \mathrm{~F}_{3} \mathrm{Br}$, all of the $\mathrm{FAA}$ test chamber volume is required for oxidation of the reactants (fuel and agent) to achieve peak temperature. This large volume of reacting agent with a high adiabatic flame temperature creates a large peak pressure rise in the constant volume chamber. In contrast, addition of $\mathrm{CF}_{3} \mathrm{Br}$ causes a reduction in the $T_{a d \text {,peak }}$ and does not result in an increase in $\eta_{\max }$. (This latter behavior is a unique property of any agent with the formula $\mathrm{CX}_{4}$, that is used in concentrations at which there are more hydrogen atoms in the chemical system than halogens, X).

The reasons for the lack of kinetic inhibition are more complex. Perfectly-stirred reactor simulations, for a wide range of inhibitor concentration and fuel-oxidizer ratio, have shown that adding the suppressant to a lean system not only adds energy to the system (and enhances the heat release, as would be expected), but increases the overall reaction rate as well. At high enough agent concentration, the overall rates are eventually reduced; however, $\mathrm{C}_{3} \mathrm{H}_{2} \mathrm{~F}_{3} \mathrm{Br}$ still failed to extinguish the FAA-ACT, despite overall reaction rates much lower than those estimated for $\mathrm{CF}_{3} \mathrm{Br}$ addition at concentrations which did extinguish the flame. The reason for this behavior has to do with which reaction zone the inhibitor is trying to extinguish. The mixture of the nearly pure fire suppressant $\mathrm{C}_{3} \mathrm{H}_{2} \mathrm{~F}_{3} \mathrm{Br}$ in air, when compressed in the endgasses of the FAA-ACT, still supports exothermic reaction. The resulting flammable regions of the chamber support very low strain flames that are much more difficult to extinguish than the high-strain flame near the impulsive release of the 2-phase fuel mixture from the simulated rupture of the aerosol can. Hence, the combination of the nearly flammable (by traditional measures) suppressant, preheating, and low strain create flames that are much more difficult to extinguish than the original fire threat that was to be suppressed. While the analyses here 
are specific to the FAA Aerosol Can Test, the work may have significance in other scenarios (for example, the combustion of marginally flammable refrigerant-air mixtures which are ignited by hydrocarbon flames, or the suppression of flames over materials of electrically energized equipment). It may be of value for researchers to explore the range of conditions for which the present results are applicable.

\section{Acknowledgements}

Helpful conversations with John Reinhardt at the FAA Technical Center are gratefully acknowledged. The work was supported by the Boeing Company, who granted NIST complete control of study design, data collection, analysis and interpretation of data, writing of the report, and the decision to submit the article for publication.

\section{References}

1. J. W. Reinhardt, Behavior of bromotrifluoropropene and pentafluoroethane when subjected to a simulated aerosol can explosion, DOT/FAA/AR-TN04/4, Federal Aviation Administration, Washington, D.C., 2004, 1-20.

2. J. W. Reinhardt, Minimum performance standard for aircraft cargo compartment halon replacement fire suppression systems (2nd update), DOT/FAA/AR-TN05/20, Federal Aviation Administration, Washington, D.C., 2005, 1-30.

3. J. W. Reinhardt, Aircraft cargo MPS test of FK-5-1-12, in: International Aircraft Systems Fire Protection Working Group, October 25-26, 2006, Atlantic City, NJ, 2006, Federal Aviation Administration, Atlantic City, NJ, 2006.

4. A. Hamins, D. Trees, K. Seshadri, H. K. Chelliah, Combustion and Flame 99 (2) (1994) 221-230.

5. E. J. P. Zegers, B. A. Williams, E. M. Fisher, J. W. Fleming, R. S. Sheinson, Combustion and Flame 121 (3) (2000) 471-487.

6. G. T. Linteris, F. Takahashi, V. R. Katta, H. K. Chelliah, O. Meier, Thermodynamic analysis of suppressant-enhanced overpressure in the FAA aerosol can simulator, in: Fire Safety Science -Proceedings of the Tenth International Symposium, M. Spearpoint, (Ed.) College Park, MD, 6/19/2011, International Association for Fire Safety Science, Boston, MA, 2011, 307-320.

7. G. T. Linteris, D. R. Burgess, V. R. Katta, F. Takahashi, H. K. Chelliah, O. Meier, Combustion and Flame 159 (2012) 1016-1025.

8. G. T. Linteris, V. I. Babushok, P. B. Sunderland, F. Takahashi, V. R. Katta, O. Meier, Proceedings of the Combustion Institute 34 (2013) 2683-2690.

9. D. R. Burgess, V. I. Babushok, G. T. Linteris, J. A. Manion, International Journal of Chemical Kinetics 47 (9) (2015) 533-563. 
10. L. A. Lovachev, V. T. Gontkovskaya, N. I. Ozerkovskaya, Combustion Science and Technology 17 (3-4) (1977) 143-151.

11. I. O. Moen, P. A. Thibault, J. H. Lee, R. Knystautas, T. Dean, C. K. Westbrook, Proceedings of the Combustion Institute 20 (2008) 1717-1725.

12. V. I. Babushok, D. R. F. Burgess, W. Tsang, A. W. Miziolek, Simulation studies on the effects of flame retardants on combustion processes in a plug reactor, in: Halon Replacements, W. Tsang; A. W. Miziolek, (Eds.), ACS Symposium Series 611, American Chemical Society, Washington, D.C., 1995, pp 275-288.

13. N. Saito, Saso, Y., Liao, C.H., Ogawa, Y., Inoue, Y., Flammability peak concentrations of halon replacements and their function as fire suppressants, in: Halon Replacements, A. W. Miziolek; W. Tsang, (Eds.), ACS Symposium Series 611, American Chemical Society, Washington, D.C., 1995, pp 243-257.

14. T. A. Moore, D. S. Diedorf, S. R. Skaggs, Update on iodides as fire extinguishing agents, in: 1993 CFC \& Halon Alternatives Conference, 1993, Washington, D.C., 1993, 800-809.

15. S. Kondo, K. Takizawa, A. Takahashi, K. Tokuhashi, A. Sekiya, Fire Safety Journal 44 (2) (2009) 192-197.

16. Y. N. Shebeko, V. V. Azatyan, I. A. Bolodian, V. Y. Navzenya, S. N. Kopyov, D. Y. Shebeko, E. D. Zamishevski, Combustion and Flame 121 (3) (2000) 542-547.

17. G. Gmurczyk, W. Grosshandler, Proceedings of the Combustion Institute 25 (1994) 1497-1503.

18. G. Holmstedt, P. Andersson, J. Andersson, Investigation of Scale Effects on Halon and Halon Alternatives Regarding Flame Extinguishing, Inerting Concerntration and Thermal Decomposition Products, in: Fourth Symposium of the International Association of Fire Safety Science, 1994, International Association of Fire Safety Science, 1994, 853-864.

19. V. R. Katta, F. Takahashi, G. T. Linteris, Combustion and Flame 144 (4) (2006) 645-661.

20. F. Takahashi, V. R. Katta, G. T. Linteris, V. I. Babushok, Proceedings of the Combustion Institute 35 (2015) 2741-2748.

21. G. Dixon-Lewis, R. J. Simpson, Proc.Combust.Inst. 16 (1) (1977) 1111-1119.

22. T. A. Moore, C. A. Weitz, R. E. Tapscott, Update on NMERI cup-burner test results, in: Papers from 1991-2006 Halon Options Technical Working Conferences (HOTWC), CD-ROM, NIST SP 9844, R. G. Gann; K. C. Whisner; S. R. Burgess; P. A. Reneke, (Eds.), 4/24/2001, National Institute of Standards and Technology, Gaithersburg, MD, 2001, 551-564.

23. J. Grigg, A. Chattaway, The evaluation of bromotrifluoropropene as a halon 1211 replacement, in: Papers from 1991-2006 Halon Options Technical Working Conferences (HOTWC), CD-ROM, NIST SP 984-4, R. G. Gann; K. C. Whisner; S. R. Burgess; P. A. Reneke, (Eds.), Albuquerque, NM, 2002, National Institute of Standards and Technology, Gaithersburg, MD, 2001, 1-10.

24. Y. Zou, N. Vahdat, M. Collins, Industrial \& Engineering Chemistry Research 40 (21) (2001) 46494653.

25. X. M. Ni, W. K. Chow, Appl Therm Eng 31 (17-18) (2011) 3864-3870.

26. V. Babushok, G. T. Linteris, D. R. Burgess Jr, P. T. Baker, Combustion and Flame 162 (2015) 11041112.

27. K. Takizawa, K. Tokuhashi, S. Kondo, Journal of Hazardous Materials 172 (2-3) (2009) 1329-1338.

28. K. Takizawa, A. Takahashi, K. Tokuhashi, S. Kondo, A. Sekiya, Combustion and Flame 141 (3) (2005) 298-307.

29. G. T. Linteris, Fire Technology 47 (1) (2011) 1-68.

30. T. Marker, Initial development of an exploding aerosol can simulator, DOT/FAA/AR-TN97/103, Federal Aviation Administration, Washington, D.C., 1998, 1-16. 
31. G. T. Linteris, Acid Gas Production in Inhibited Propane-Air Diffusion Flames, in: Halon Replacements, A. Miziolek; W. Tsang, (Eds.), ACS Symposium Series 611, American Chemical Society, Washington, D.C., 1995, pp 225-242.

32. V. I. Babushok, G. T. Linteris, P. T. Baker, Combustion and Flame 162 (5) (2015) 2307-2310.

33. A. E. Lutz, F. M. Rupley, R. J. Kee, W. C. Reynolds, E. Meeks, EQUIL: A CHEMKIN implementation of STANJAN for computing chemical equilibria, S. N. Laboratories, Reaction Design, Inc., 6500 Dublin Boulevard, Dublin, CA 94568. Software and manual authorized by Ellen Meeks and Fran Rupley, 1998, 15.

34. S. Gordon, McBride, B.J., Computer program for calculation of complex chemical equilibrium compositions and applications, NASA Reference Publication 1311, Cleveland, OH, 1996.

35. H. Wang, X. You, K. W. Jucks, S. G. Davis, A. Laskin, F. Egolfopoulos, C. K. Law, USC Mech Version II. High-temperature combustion reaction model of $\mathrm{H} 2 / \mathrm{CO} / \mathrm{C} 1-\mathrm{C} 4$ compounds. $<$ http://ignis.usc.edu/USC Mech II.htm> (2015).

36. J. Li, A. Kazakov, F. L. Dryer, Journal of Physical Chemistry A 108 (38) (2004) 7671-7680.

37. D. R. Burgess, M. R. Zachariah, W. Tsang, P. R. Westmoreland, Progress in Energy and Combustion Science 21 (6) (1995) 453-529.

38. D. L'Esperance, B. A. Williams, J. W. Fleming, Combustion and Flame 117 (4) (1999) 709-731.

39. Y. Saso, D. L. Zhu, H. Wang, C. K. Law, N. Saito, Combustion and Flame 114 (3-4) (1998) 457-468.

40. V. I. Babushok, G. T. Linteris, O. Meier, Combust Flame 159 (2012) 3569-3575.

41. E. Goos, A. Burcat, B. Ruscic, Extended Third Millennium Thermodynamic Database for Combustion and Air-Pollution Use with updates from Active Thermochemical Tables. $<$ ftp://ftp.technion.ac.il/pub/supported/aetdd/thermodynamics/BURCAT.THR> (August).

42. O. Sanogo, J. L. Delfau, R. Akrich, C. Vovelle, Journal De Chimie Physique Et De Physico-Chimie Biologique 93 (11-12) (1996) 1939-1957.

43. C. H. Osorio, A. J. Vissotski, E. L. Petersen, M. S. Mannan, Combustion and Flame 160 (6) (2013) 1044-1059.

44. G. T. Linteris, M. D. Rumminger, V. I. Babushok, W. Tsang, Proceedings of the Combustion Institute 28 (0) (2000) 2965-2972.

45. J. L. Pagliaro, G. T. Linteris, P. B. Sunderland, P. T. Baker, Combustion and Flame 162 (1) (2015) 41-49.

46. J. L. Pagliaro, N. Bouvet, G. T. Linteris, Combustion and Flame, "Premixed flame inhibition by CF3Br and C3H2F3Br (2-BTP)," (2015) In Preparation.

47. R. J. Kee, J. F. Grcar, M. D. Smooke, J. A. Miller, A fortran computer program for modeling steady laminar one-dimensional premixed flames, SAND85-8240, Sandia National Laboratories, Livermore, CA, 1991.

48. F. A. Williams, Journal of Fire and Flammability 5 (1974) 54-63.

49. R. B. Barat, Chemical Engineering Science 56 (2001) 2761-2766.

50. S. Liu, M. C. Soteriou, M. B. Colket, J. A. Senecal, Fire Safety Journal 43 (8) (2008) 589-597.

51. A. Y. Snegirev, A. S. Tsoy, Proceedings of the Combustion Institute 35 (2015) 2519-2526.

52. P. Glarborg, R. J. Kee, J. F. Grcar, J. A. Miller, PSR: A FORTRAN program for modeling well-stirred reactors, SAND86-8209, Sandia National Laboratories, Albuquerque, NM, 1986, 1-54.

53. R. A. Ogle, Process Safety Progress 18 (3) (1999) 170-177.

54. J. W. Reinhardt, Prevention of a simulated aerosol can explosion with a mixture of Halon 1301 and nitrogen, DOT/FAA/AR-TN08/49, F. A. Administration, Washington, D.C., 2008, 1-16.

55. I. Glassman, Combustion, Academic Press, San Diego, CA, 1996.

56. G. T. Linteris, D. R. Burgess, V. Babushok, M. Zachariah, W. Tsang, P. Westmoreland, Combustion and Flame 113 (1-2) (1998) 164-180. 
57. G. T. Linteris, J. A. Manion, W. Tsang, D. R. Burgess Jr, V. Babushok, V. R. Katta, F. Takahashi, P. B. Sunderland, J. L. Pagliaro, Overpressure in the FAA aerosol can test with halon replacements, in: The Seventh Triennial International Fire \& Cabin Safety Research Conference, Dec. 3-5, 2013, Philadelphia, PA, 2013, Federal Aviation Administration, Atlantic City, NJ, 2013.

58. B. P. Carnazza, J. G. Owens, P. E. Rivers, J. S. Schmeer, FK-5-1-12 Performance characteristitics: recent developments., in: Papers from 1991-2006 Halon Options Technical Working Conferences (HOTWC), CD-ROM, NIST SP 984-4, R. G. Gann; S. R. Burgess; K. C. Whisner; P. A. Reneke, (Eds.), National Institute of Standards and Technology, Gaithersburg, MD. 
Table 1 - Stoichiometric agent concentration and calculated burning velocity for pure suppressant-air mixtures $[40,46]$.

\begin{tabular}{|l|c|c|c|c|}
\hline \multicolumn{1}{|c|}{ Agent } & Oxidizer & To, $\mathrm{K}$ & Stoic conc. & Peak Burning velocity, cm/s \\
\hline $\mathrm{C}_{2} \mathrm{~F}_{5} \mathrm{H}$ & air & 400 & 0.174 & 1.6 \\
\hline $\mathrm{C}_{3} \mathrm{H}_{2} \mathrm{~F}_{3} \mathrm{Br}$ & air & 400 & 0.065 & 2.2 \\
\hline $\mathrm{C}_{3} \mathrm{H}_{2} \mathrm{~F}_{3} \mathrm{Br}$ & air & 500 & 0.063 & 3.6 \\
\hline $\mathrm{C}_{6} \mathrm{~F}_{12} \mathrm{O}$ & air & 400 & 0.077 & 0.37 \\
\hline $\mathrm{CF}_{3} \mathrm{Br}\left(\mathrm{P}_{0}=3\right.$ bar $)$ & oxygen & 500 & 0.65 & 0.27 \\
\hline
\end{tabular}

Table 2 - Cup-burner ( $\mathrm{n}$-heptane fuel) minimum extinguishing concentrations for suppressantair mixtures.

\begin{tabular}{|l|c|}
\hline \multicolumn{1}{|c|}{ Agent } & $\begin{array}{c}\text { Minimum Extinguishing Concentration } \\
\text { (volume fraction in air, \%) }\end{array}$ \\
\hline $\mathrm{CF}_{3} \mathrm{Br}$ & $2.9[22]$ \\
\hline $\mathrm{C}_{2} \mathrm{~F}_{5} \mathrm{H}$ & $9.4[22]$ \\
\hline $\mathrm{C}_{3} \mathrm{H}_{2} \mathrm{~F}_{3} \mathrm{Br}$ & $2.6[22]$ \\
\hline $\mathrm{C}_{6} \mathrm{~F}_{12} \mathrm{O}$ & $4.5[58]$ \\
\hline
\end{tabular}




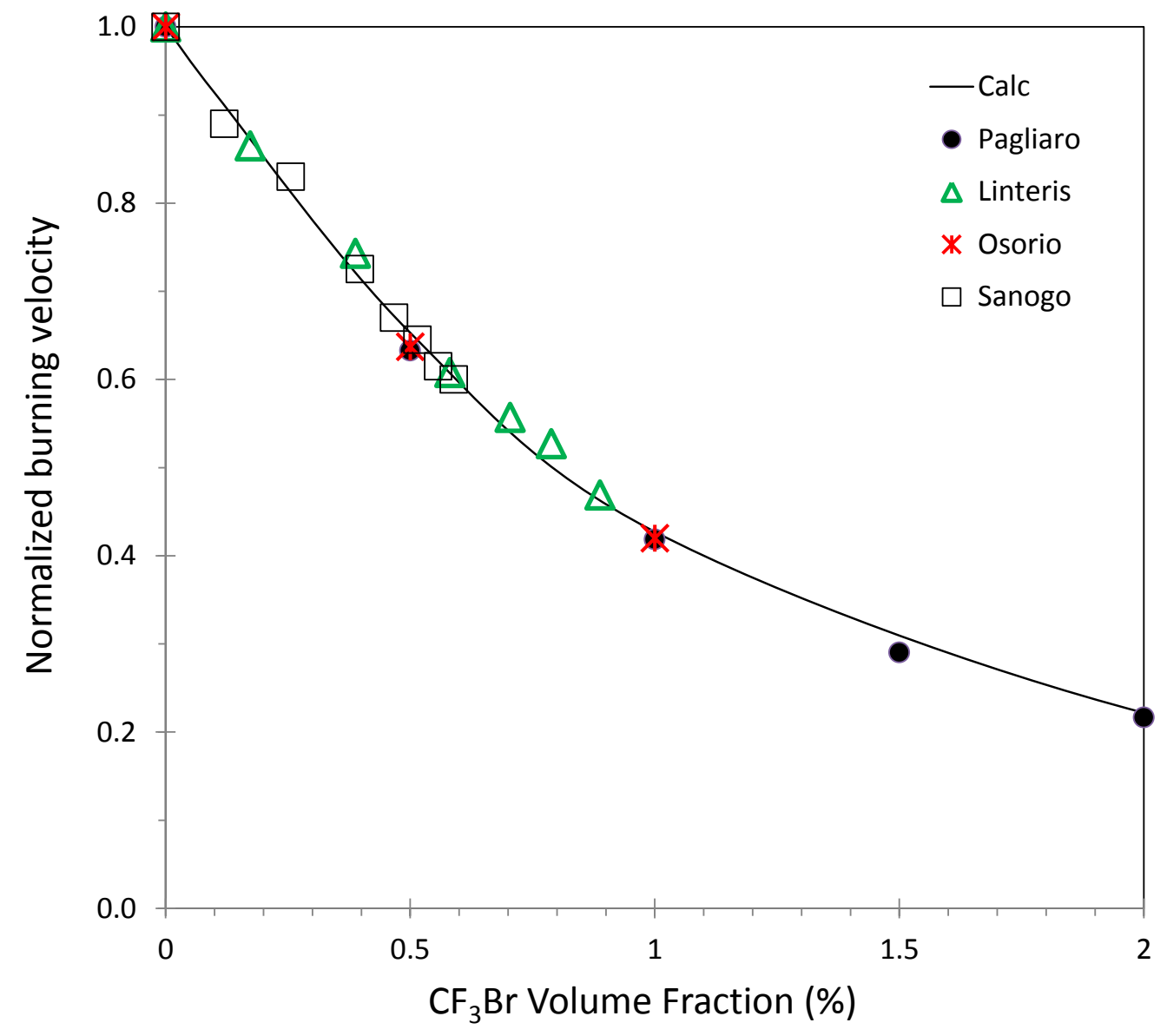

Fig. 1. - Measured [42-45] and calculated premixed, laminar burning velocity (normalized by the uninhibited value) for initially stoichiometric methane-air flames with added $\mathrm{CF}_{3} \mathrm{Br}$. 


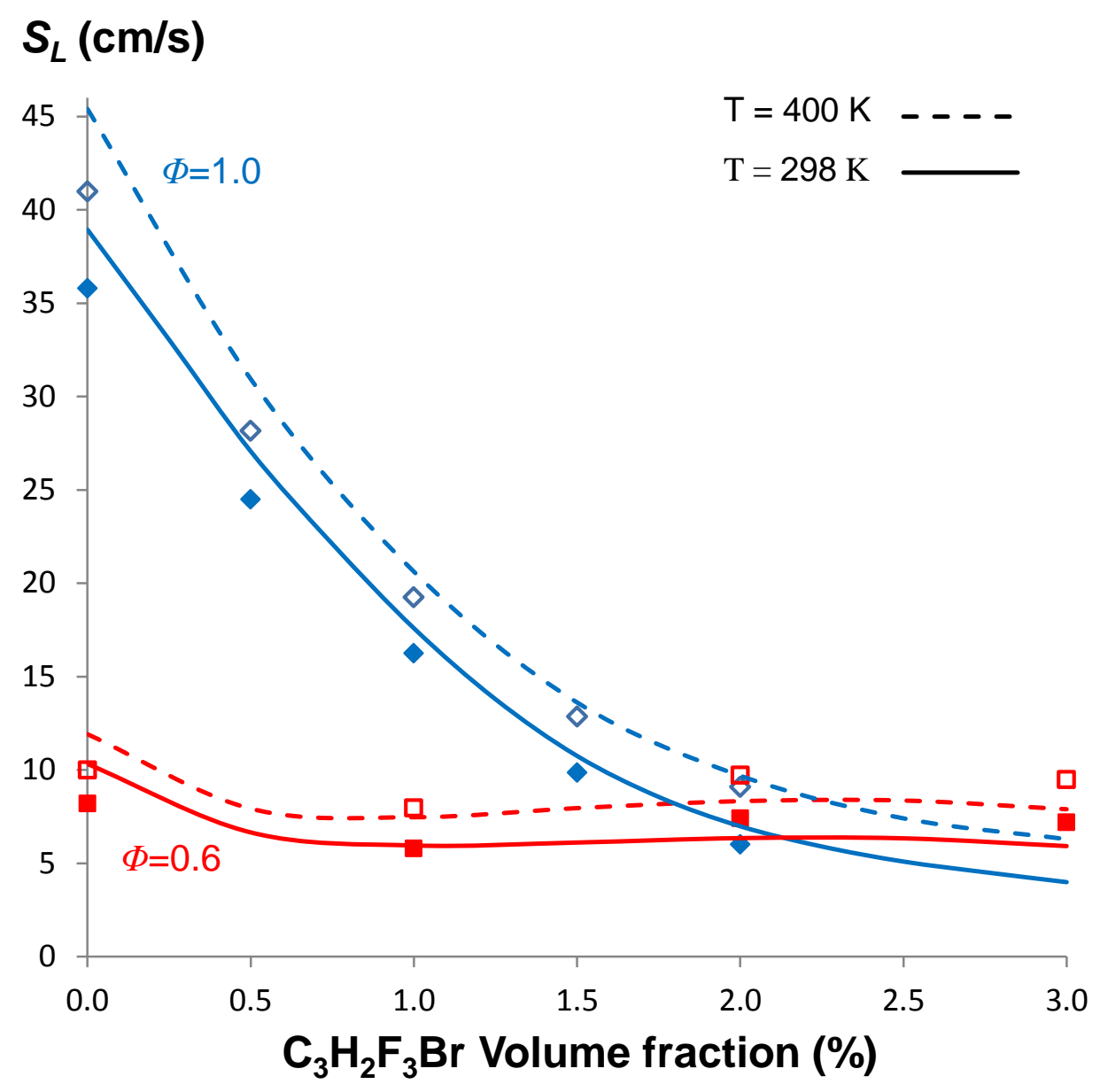

Fig. 2. - Measured and calculated burning velocity of methane-air mixtures with added $\mathrm{C}_{3} \mathrm{H}_{2} \mathrm{~F}_{3} \mathrm{Br}$ (initial conditions: solid lines and symbols, $298 \mathrm{~K}, 0.10133 \mathrm{MPa}$; dotted lines and open symbols, $400 \mathrm{~K}, 0.304 \mathrm{MPa}$; and initial $\mathrm{CH}_{4}$-air equivalence ratios of 0.6 and 1.0). 

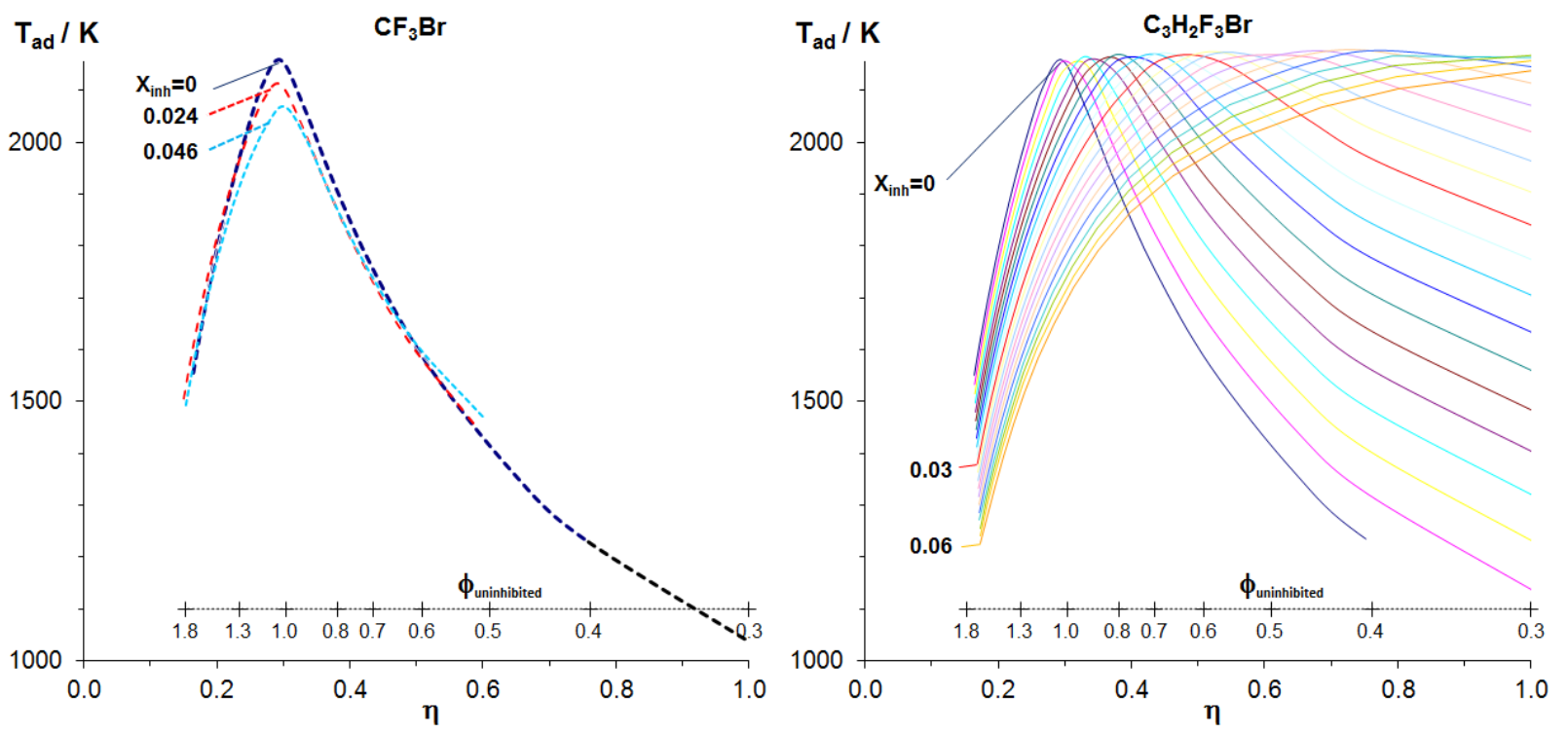

Fig. 3. Calculated adiabatic combustion temperature $\left(T_{a d}\right)$ for fraction $(\eta)$ of chamber volume involved in reaction with the aerosol can test fuel (left frame: $\mathrm{CF}_{3} \mathrm{Br}$, right: $\mathrm{C}_{3} \mathrm{H}_{2} \mathrm{~F}_{3} \mathrm{Br}$ ). 


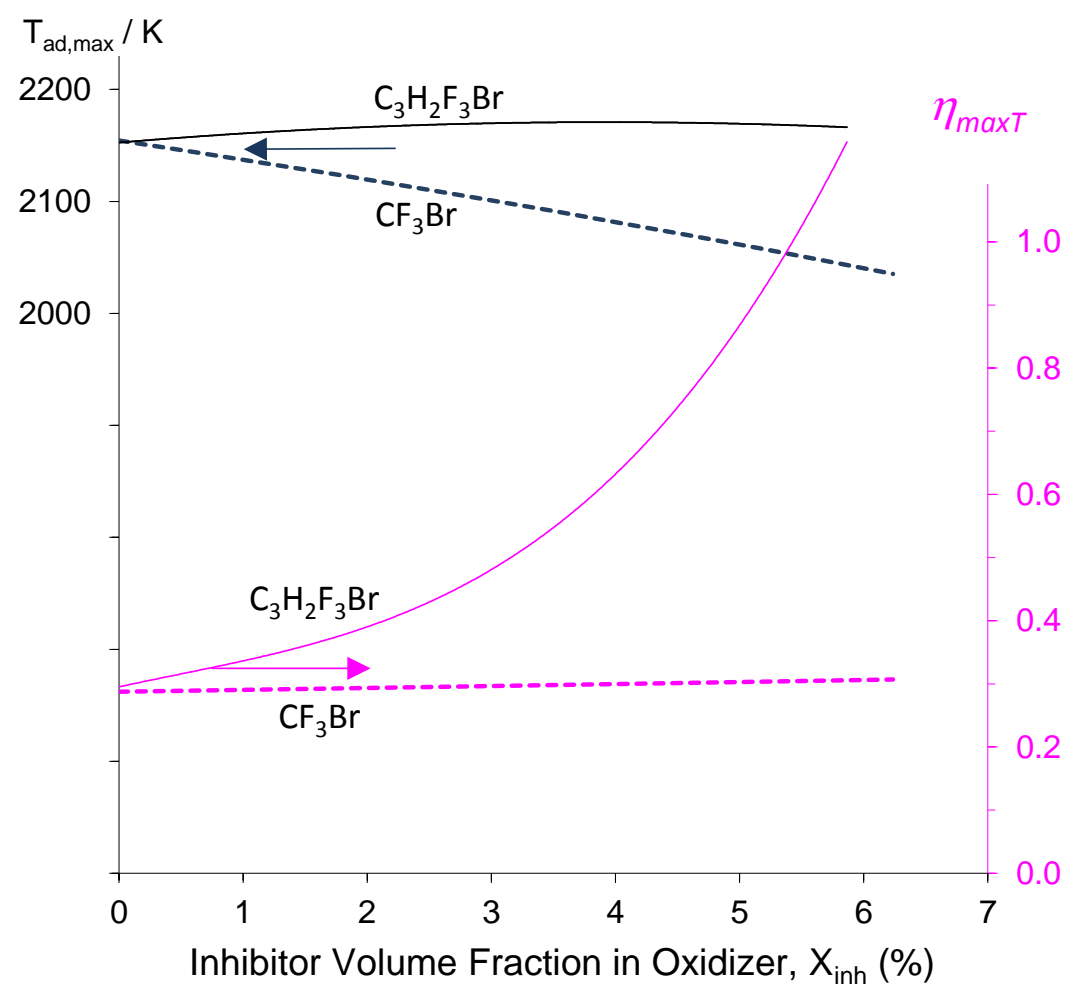

Fig. 4. Calculated $T_{\text {ad,peak }}$ (left scale), and fraction $\left(\eta_{\max }\right)$ of chamber oxidizer volume (right scale) required to achieve the $T_{a d, p e a k}$ as a function of $X_{\text {inh }}$, for $\mathrm{CF}_{3} \mathrm{Br}$ and $\mathrm{C}_{3} \mathrm{H}_{2} \mathrm{~F}_{3} \mathrm{Br}$. 


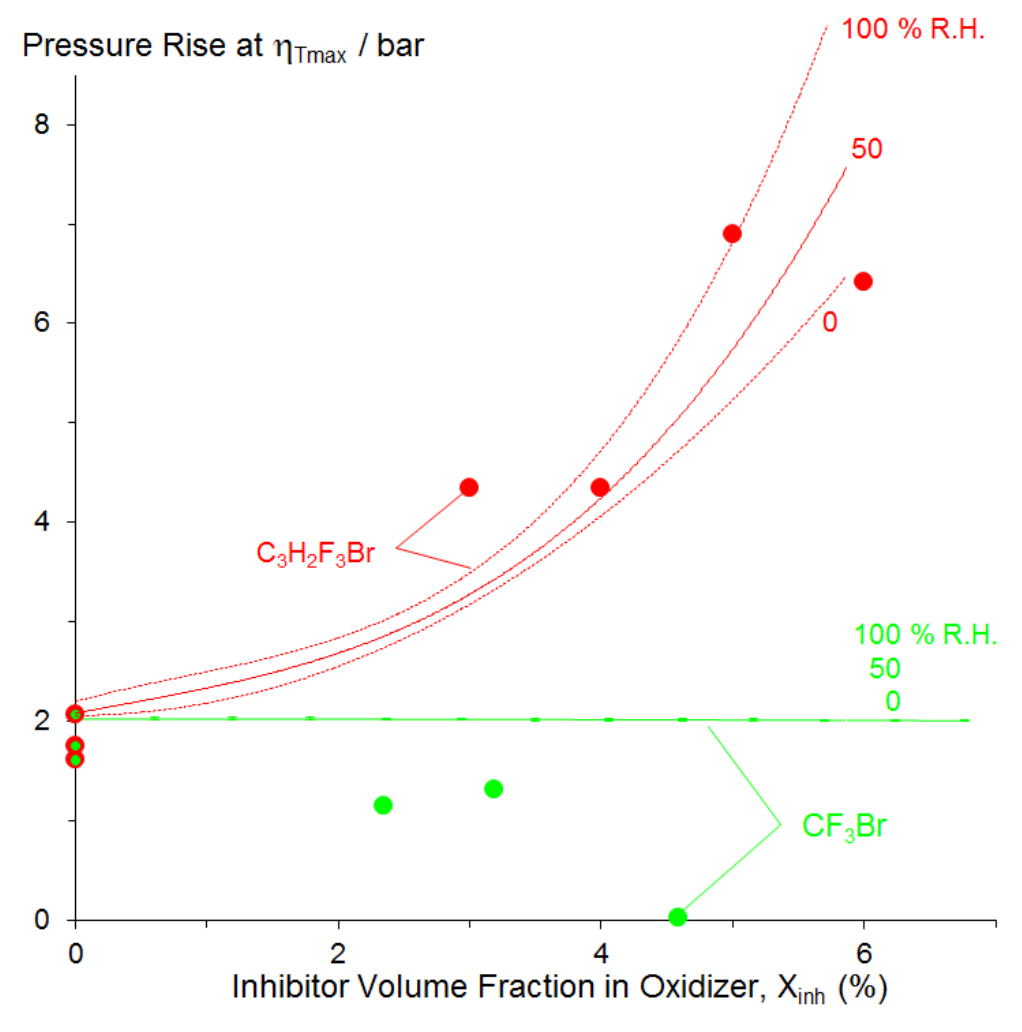

Fig. 5. Calculated maximum explosion pressure (lines) and FAA measurements (dots) in the FAA Aerosol Can Test with added $\mathrm{C}_{3} \mathrm{H}_{2} \mathrm{~F}_{3} \mathrm{Br}$ or $\underline{\mathrm{CF}_{3}} \underline{\mathrm{Br}}$. 

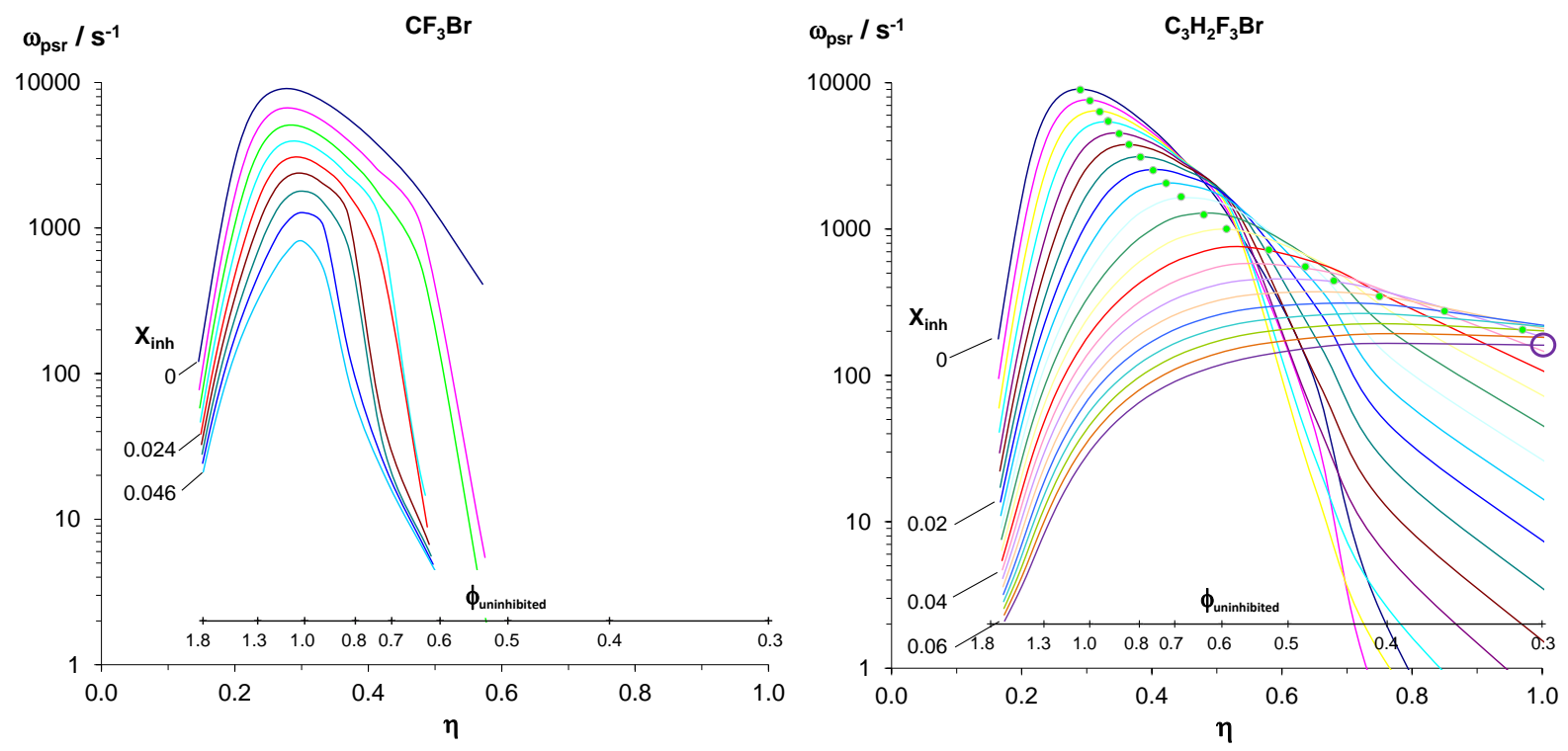

Fig. 6. Overall chemical rate $\omega_{p s r}$ vs $\eta$ (left frame: $\mathrm{CF}_{3} \mathrm{Br}$, right: $\mathrm{C}_{3} \mathrm{H}_{2} \mathrm{~F}_{3} \mathrm{Br}$ ) for fuel of FAA Aerosol Can Test. 


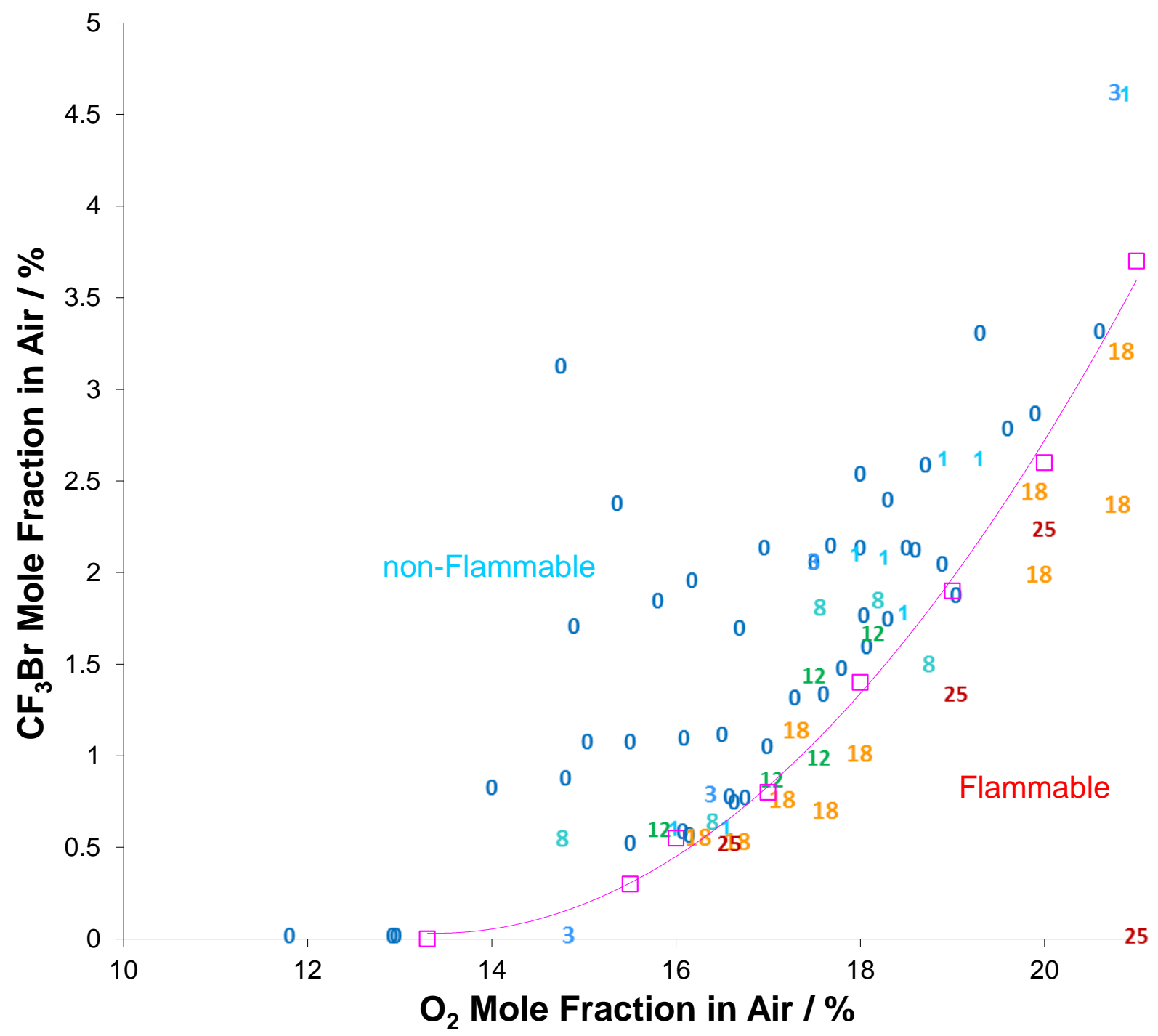

Fig. 7. Experimentally measured [54] final explosion pressure rise (psi) in the FFA-ACT as a function of added $\mathrm{CF}_{3} \mathrm{Br}$ or $\mathrm{N}_{2}$ in the oxidizer. 


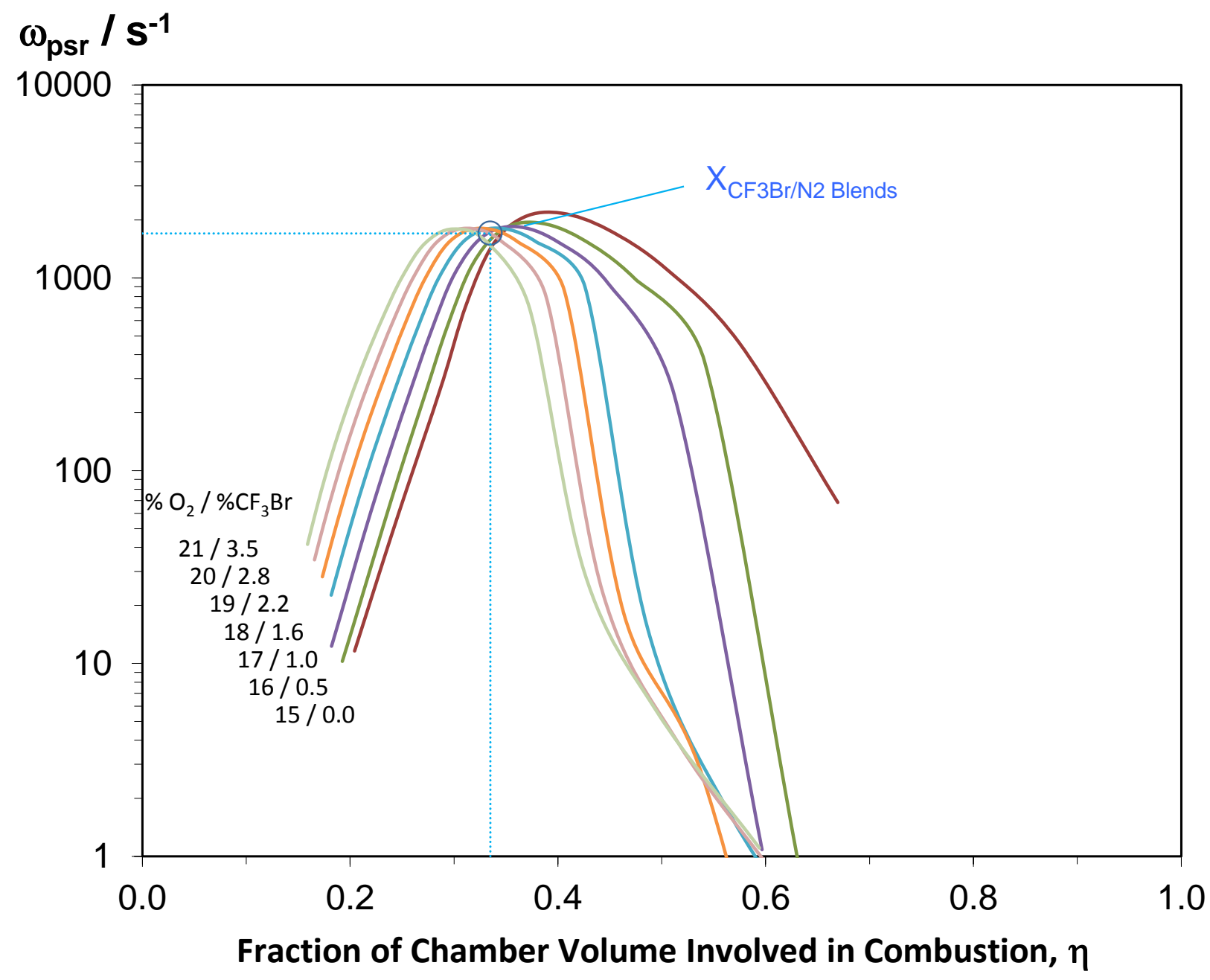

Fig. 8 - Perfectly-stirred reactor (PSR) overall reaction rate $\left(\omega_{p s r}\right)$ for inerting mixtures of $\mathrm{CF}_{3} \mathrm{Br}$ and $\mathrm{N}_{2}$, as a function of the chamber volume fraction involved in combustion $\eta$. Each curve corresponds to the given initial volume fraction of $\mathrm{CF}_{3} \mathrm{Br}$ and $\mathrm{N}_{2}$ in the chamber. 


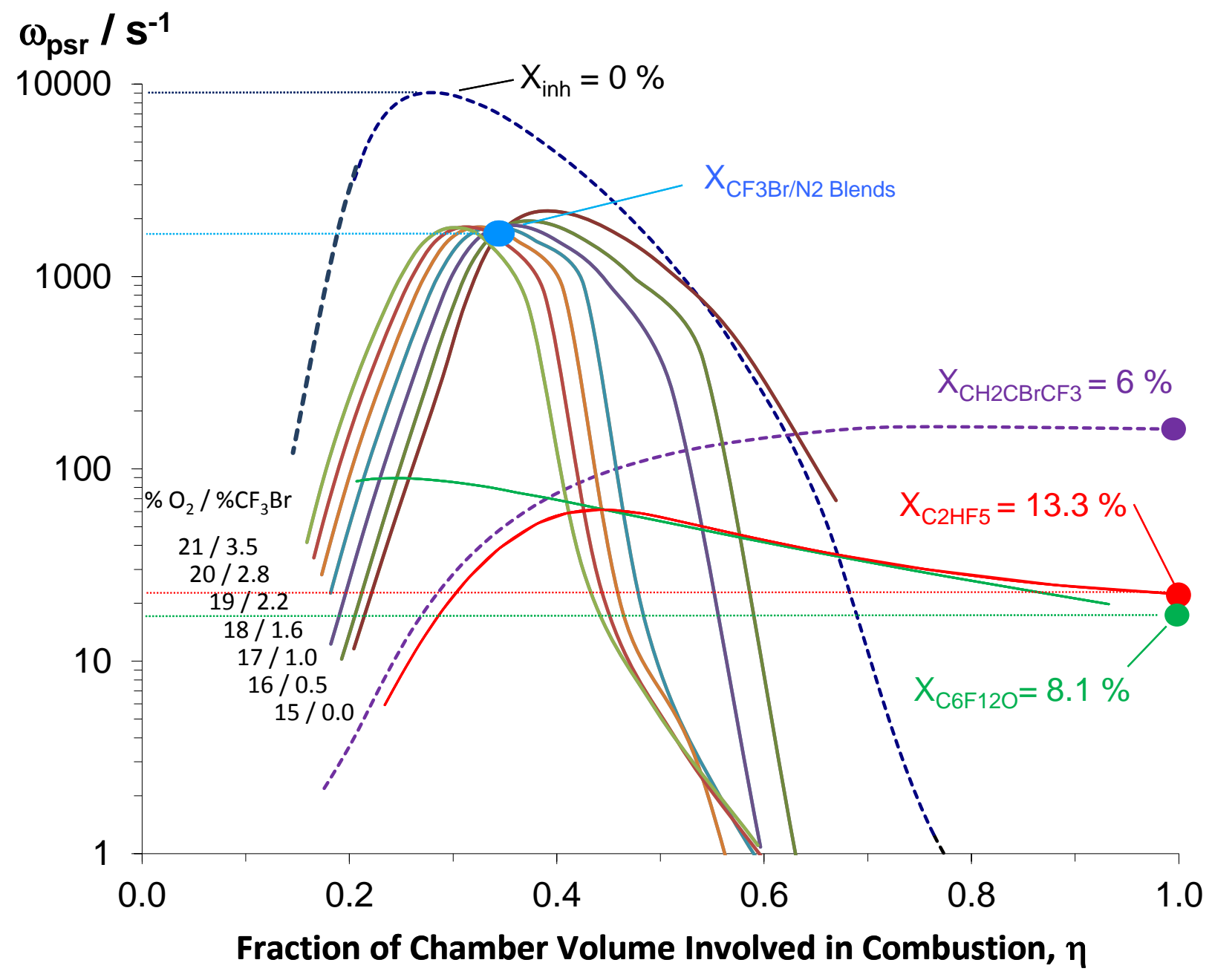

Fig. 9. PSR overall rate $\omega_{p s r}$ as a function of $\eta$ in the FAA-ACT with added $\mathrm{CF}_{3} \mathrm{Br} / \mathrm{N}_{2}$ mixtures, $\mathrm{C}_{2} \mathrm{HF}_{5}$, and $\mathrm{C}_{6} \mathrm{~F}_{12} \mathrm{O}$ at their inerting volume fraction. 


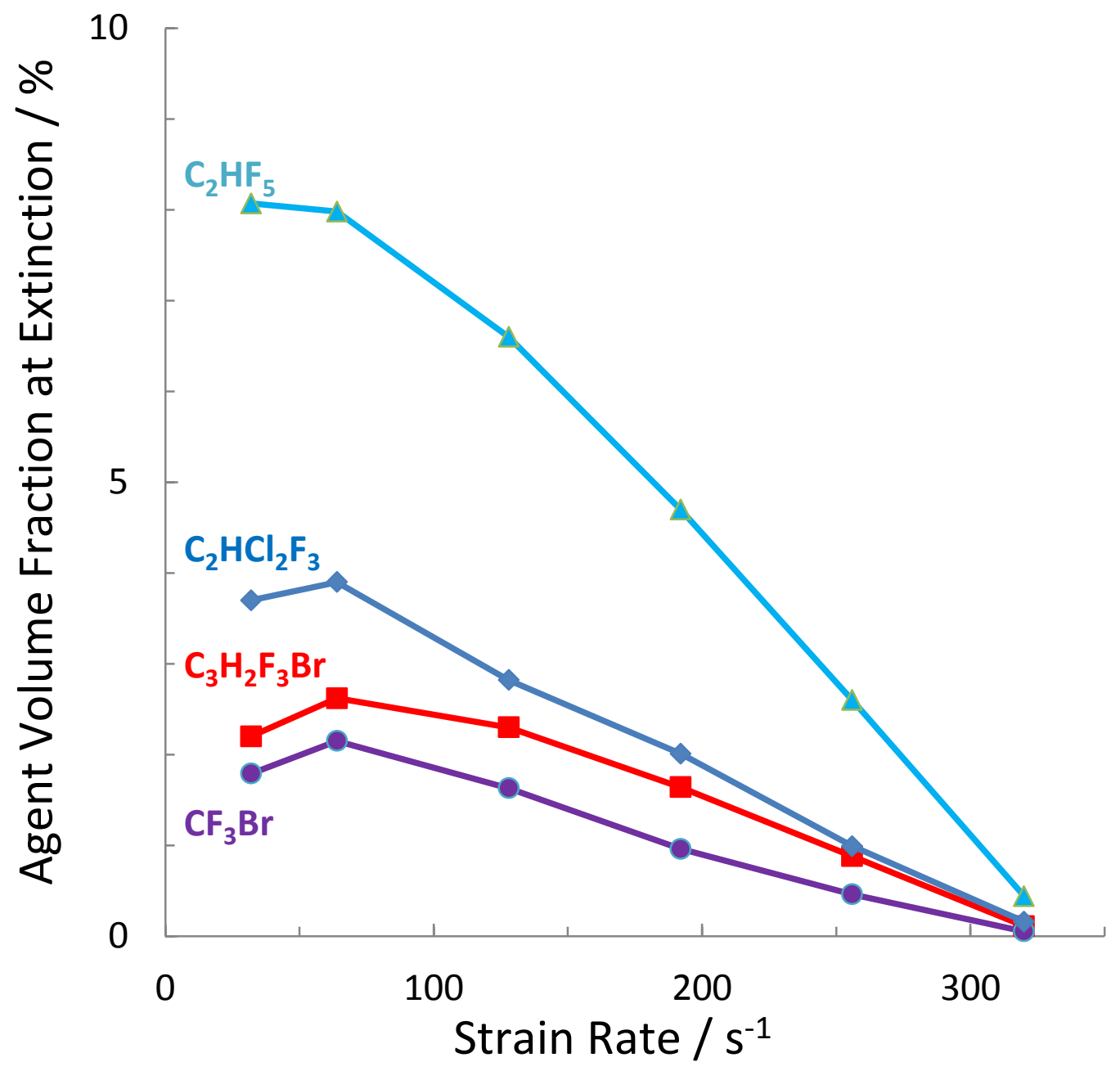

Fig. 10. Extinction agent volume fraction in the oxidizer stream of a methane-air counterflow diffusion flame with added $\mathrm{C}_{2} \mathrm{HF}_{5}, \mathrm{CF}_{3} \mathrm{CHCl}_{2}, \mathrm{C}_{3} \mathrm{H}_{2} \mathrm{~F}_{3} \mathrm{Br}$, or $\mathrm{CF}_{3} \mathrm{Br}$ [57]. 


\section{Figure Captions}

Fig. 1. - Measured [42-45] and calculated premixed, laminar burning velocity (normalized by the uninhibited value) for initially stoichiometric methane-air flames with added $\mathrm{CF}_{3} \mathrm{Br}$.

Fig. 2. - Measured and calculated burning velocity of methane-air mixtures with added $\mathrm{C}_{3} \mathrm{H}_{2} \mathrm{~F}_{3} \mathrm{Br}$ (initial conditions: solid lines and symbols, $298 \mathrm{~K}, 0.10133 \mathrm{MPa}$; dotted lines and open symbols, $400 \mathrm{~K}, 0.304 \mathrm{MPa}$; and initial $\mathrm{CH}_{4}$-air equivalence ratios of 0.6 and 1.0).

Fig. 3. Calculated adiabatic combustion temperature $\left(T_{a d}\right)$ for fraction $(\eta)$ of chamber volume involved in reaction with the aerosol can test fuel (left frame: $\mathrm{CF}_{3} \mathrm{Br}$, right: $\mathrm{C}_{3} \mathrm{H}_{2} \mathrm{~F}_{3} \mathrm{Br}$ ).

Fig. 4. Calculated $T_{\text {ad,peak }}$ (left scale), and fraction $\left(\eta_{\text {maxt }}\right)$ of chamber oxidizer volume (right scale) required to achieve the $T_{a d, p e a k}$ as a function of $X_{\text {inh }}$, for $\mathrm{CF}_{3} \mathrm{Br}$ and $\mathrm{C}_{3} \mathrm{H}_{2} \mathrm{~F}_{3} \mathrm{Br}$.

Fig. 5. Calculated maximum explosion pressure (lines) and FAA measurements (dots) in the FAA Aerosol Can Test with added $\mathrm{C}_{3} \mathrm{H}_{2} \mathrm{~F}_{3} \mathrm{Br}$ or $\mathrm{CF}_{3} \mathrm{Br}$.

Fig. 6. Overall chemical rate $\omega_{p s r}$ vs $\eta$ (left frame: $\mathrm{CF}_{3} \mathrm{Br}$, right: $\mathrm{C}_{3} \mathrm{H}_{2} \mathrm{~F}_{3} \mathrm{Br}$ ) for fuel of FAA Aerosol Can Test.

Fig. 7. Experimentally measured [54] final explosion pressure rise (psi) in the FFA-ACT as a function of added $\mathrm{CF}_{3} \mathrm{Br}$ or $\mathrm{N}_{2}$ in the oxidizer.

Fig. 8 - Perfectly-stirred reactor (PSR) overall reaction rate $\left(\omega_{p s r}\right)$ for inerting mixtures of $\mathrm{CF}_{3} \mathrm{Br}$ and $\mathrm{N}_{2}$, as a function of the chamber volume fraction involved in combustion $\eta$. Each curve corresponds to the given initial volume fraction of $\mathrm{CF}_{3} \mathrm{Br}$ and $\mathrm{N}_{2}$ in the chamber. 
Fig. 9. PSR overall rate $\omega_{p s r}$ as a function of $\eta$ in the FAA-ACT with added $\mathrm{CF}_{3} \mathrm{Br} / \mathrm{N}_{2}$ mixtures, $\mathrm{C}_{2} \mathrm{HF}_{5}$, and $\mathrm{C}_{6} \mathrm{~F}_{12} \mathrm{O}$ at their inerting volume fraction.

Fig. 10. Extinction agent volume fraction in the oxidizer stream of a methane-air counterflow diffusion flame with added $\mathrm{C}_{2} \mathrm{HF}_{5}, \mathrm{CF}_{3} \mathrm{CHCl}_{2}, \mathrm{C}_{3} \mathrm{H}_{2} \mathrm{~F}_{3} \mathrm{Br}$, or $\mathrm{CF}_{3} \mathrm{Br}$ [57]. 